\title{
Plants Bioclimatic Affinity Groups in China: Observed vs. Simulated Ranges
}

\author{
Kang-you Huang ${ }^{1,2}$, Zhuo Zheng ${ }^{1}$, Louis François ${ }^{3}$, Dong-sheng Guan ${ }^{4}$ and Rachid Cheddadi ${ }^{*}, 2$ \\ ${ }^{I}$ Department of Earth Sciences, Sun Yat-Sen University, 510275 Guangzhou, China \\ ${ }^{2}$ Université Montpellier 2, CNRS, Institut des Sciences de l'Évolution, Place Eugène Bataillon, 34095 Montpellier cedex \\ 05, France \\ ${ }^{3}$ Climate and Biogeochemical Cycles Modelling Unit (UMCCB). Astrophysics and Geophysics Department. \\ Université de Liège, Bât B5c, 17 Allée du 6 Août, B-4000 Liège, Belgium \\ ${ }^{4}$ School of Environmental Science and Engineering, Sun Yat-Sen University, 510275 Guangzhou, China
}

\begin{abstract}
Predicting future ecosystems changes is necessary for better managing human resources. Such forecasting requires robust vegetation models which have been tested versus observed field data. Nowadays, it is very common that a simulation model is firstly validated using modern observed data and then tested versus palaeodata. In a sense, ecological data represent the natural laboratory for modelers. Thus, palaeo and actuo-ecological data are key points when dealing with predicting future changes. The present work represents the first step in such data-model comparison approach. Here, we use only modern plants distributions to test the robustness of our ecosystems definitions and use these definitions for testing a dynamic vegetation model.

We have defined twenty-nine Bioclimatic affinity groups (BAGs) for 196 dominant plant species including trees, shrubs and herbs in China. These BAGs are characterized by the phenology and the climatic tolerances of the species they include. They are detailed enough to describe all vegetation types in China including the tropical, the subtropical, the temperate and the high altitude (Tibet Plateau) ecosystems.

The climatic thresholds of these 29 BAGs were then used to test and validate a global dynamic vegetation model (CARAIB). The simulated BAGs are in good agreement with those observed in China, especially in the Tibetan Plateau and in the subtropical ecosystems. Broadly, all simulated BAGs fit quite well with the modern distribution. However, they all cover larger areas than the observed distributions, especially in the temperate region and in some areas in the northwest and the tropical zone. These discrepancies between simulated and observed distributions are related to the fact that the vegetation models simulate potential distributions. In China during recent decades natural ecosystems, mostly in the temperate zone, have been strongly altered in their species composition and geographical extent by different human activities such as the intense cultivation, deforestation, introduction of fast growing species and grazing.
\end{abstract}

Keywords: Bioclimate, vegetation, cluster analysis, vegetation modeling, China.

\section{INTRODUCTION}

Managing future ecosystem resources requires robust simulation models which are capable of reproducing as accurately as possible observed ones. These observations can be either modern or from a past period where reliable data is available. Some fifteen years ago the PMIP project ("Palaeo Modeling Intercomparison Project", Joussaume and Taylor, 1995) initiated comparisons of model climate simulations versus reconstructed climate variables from observed palaeodata at 6000 and 21000 years BP. Following the PMIP initiative, the BIOME6000 project (Prentice et al. 1997) undertook the validation of a dynamic vegetation model

*Address correspondence to this author at the Institut des Sciences de l'Évolution, Université Montpellier II, CNRS, Place Eugène Bataillon, 34095 Montpellier cedex 05, France; Tel: 0467143271; Fax: 0467144044; E-mail: rachid.cheddadi@univ-montp2.fr

Special Issue Editor: Valenti Rull using both modern and fossil pollen data at 6000 years BP. The approach used in all these data-model comparisons initiatives relies on the paleo and actuo-ecology knowledge to improve the models towards an overall aim that is to predict accurately future changes. One of the aims of the present work is to show that modern ecology has one common objective with palaeoecology that is improving our modeling capacity.

Since the industrial period, the combustion of fossil fuels has increased the atmospheric carbon dioxide concentration from 280 to $379 \mathrm{ppmv}$ and it is expected to reach 540 970 ppmv in 2100 under non-mitigation scenarios (IPCC 2001, 2007). The consequent greenhouse effect will have a significant impact on terrestrial ecosystems. The main objective of the International Geosphere-Biosphere Programme (IGBP) is to predict future climate change and its potential impact on the ecosystems. This goal relies on the accuracy of 
climate predictions and of simulated climate-vegetation relationships (IGBP 1990).

Comprehending the modern relationship between plant geographical distributions and climatic parameters is essential for better predicting future ecosystem responses. Vegetation models simulate these responses under different climate scenarios. Biomes and related climatic parameters have been used to simulate vegetation distribution at global scale (Prentice et al. 1992, Haxeltine and Prentice 1996, Kaplan 2001, Otto et al. 2002). These biomes are based on Plant Functional Types (PFTs) (Prentice et al. 1992) which are themselves defined as sets of plant taxa that are similar biologically and respond similarly to environmental change (Smith et al. 1996). In this PFT definition, the functional properties of the plant species (Díaz and Cabido 1997) are not taken into account.

In Europe, Laurent et al. (2004) proposed to use the modern geographical ranges of species, their phenology and related climatic variables for defining bioclimatic affinity groups (BAGs). These BAGs proved to be detailed enough to define ecosystem distributions at the regional scale more accurately than PFTs (Laurent et al. 2004) and may be used for validating a dynamic global vegetation model (DGVM) (Laurent et al. 2008).

Here we have used the BAG approach for defining vegetation units in China and for validating a DGVM. China is a large and mountainous country where more than half of the territory is occupied by mountains and high plateaus. It also spans several climatic zones and has complex vegetation. Earlier studies have characterized ecosystems distribution in China for the present and at 6000 years BP using the PFT (and biomes) concept from pollen data (Yu 1998, Sun et al. 1999, Yu et al. 2000, Members of China Quaternary Pollen Database 2001). Ni (2001) divided the Chinese ecosystems into 39 PFTs and 21 biomes according to the geographical distribution, the eco-physiognomy and phenology of the dominant species in 103 vegetation formations ( $\mathrm{Ni}$ 2001). However, the plant taxa and the detailed climatic parameters for these 39 PFTs are not stated in his study. Weng et al. (2005) proposed a two-step hierarchical classification system for 18 PFTs based on six key plant attributes: permanence of above ground live biomass (woody vs. herbaceous), leaf longevity (evergreen vs. deciduous), leaf structure (broadleaved vs. conifer), photosynthetic pathways, drought resistance, and temperature tolerance. The definition of PFTs in these previous studies in China are different but in all cases they characterize quite well most of the vegetation units in China. However, we found them not accurate enough in terms of climate thresholds for validating a vegetation model, particularly for the subtropical zone.

The aim of the present paper is to accurately define ecosystems at both local and regional scales in China and to show that their climate thresholds may be used for validating a global dynamic vegetation model. We are aware that the modern plant distributions are biased by human inferences (Fig. 1). We do consider this work on modern data only as a contribution to a bigger ecological jigsaw puzzle which should integrate also palaeoecology for validating our model with unbiased data. The overall objective is to better manage future ecological resources.

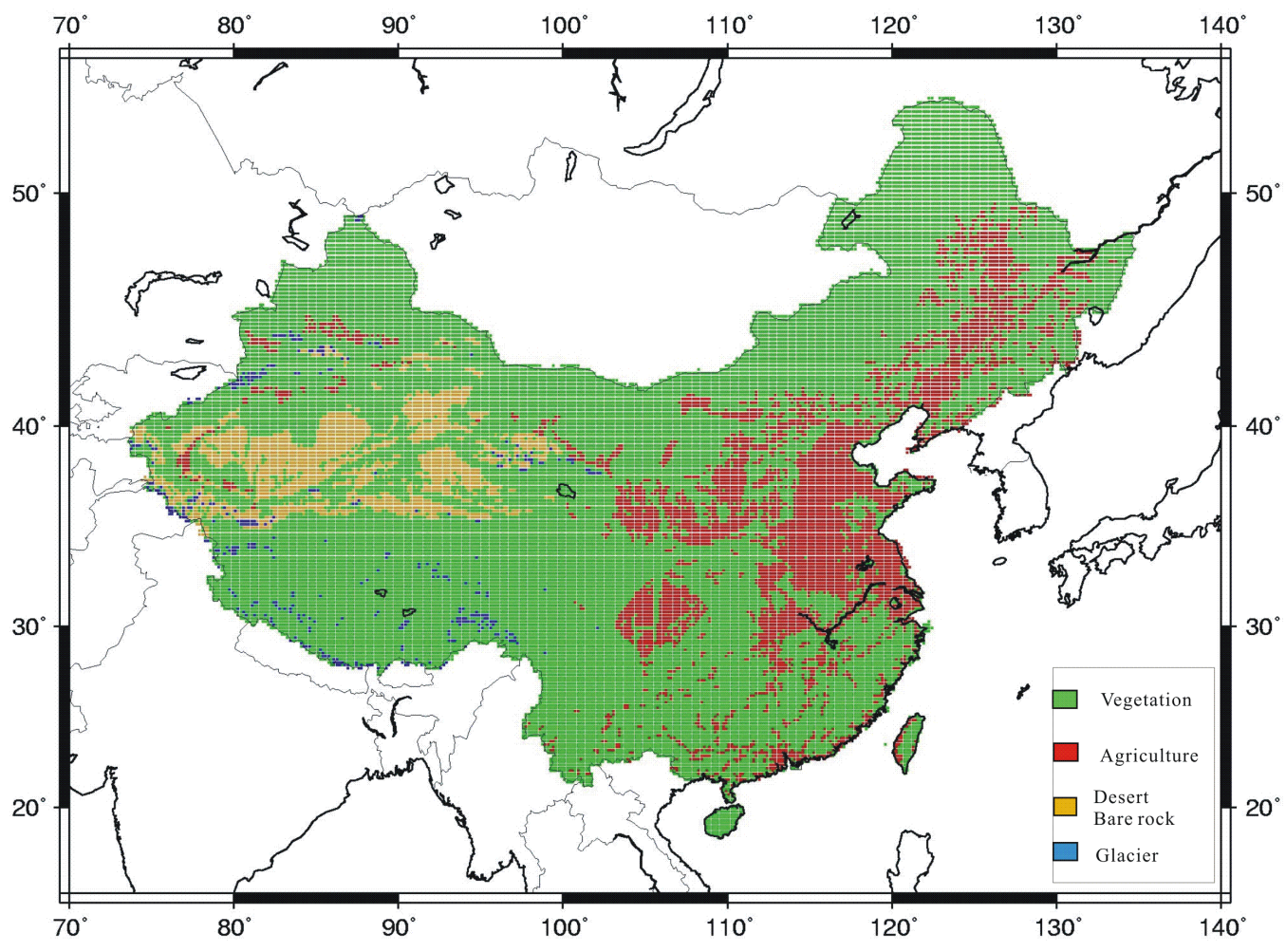

Fig. (1). Map of China showing the locations of intense agricultural practices. 


\section{APPROACH}

\section{Modern Plant Distribution and Climatology}

The spatial distribution of 196 dominant Chinese plant species from the "Vegetation Map of China" (Hou 2001) was georeferenced on a $10^{\prime} \times 10^{\prime}$ grid using a GIS. The plant species include 89 trees, 63 shrubs and 44 herbs (Huang et al. 2008).

Climate data were obtained from the Climatic Research Unit (CRU) database (http://www.cru.uea.ac.uk/cru/data/ tmc.htm). The dataset consists of a global $10^{\prime} \times 10^{\prime}$ longitude and latitude grid of mean monthly surface climate over land areas. The grid climate data was interpolated using a thin plate spline from a dataset of meteorological stations and represent mean climates from 1961 to 1990 (New et al. 2002). The climate dataset that we have used includes: (1) monthly mean temperature, (2) monthly mean precipitation, (3) diurnal temperature range, (4) ground frost frequency, (5) relative humidity index (Rhu), and (6) percentage of sunshine hours. The growing degree days above $5^{\circ} \mathrm{C}$ (GDD5) were computed with a stochastic weather generator (Hubert et al. 1998) implemented within the vegetation model (CARAIB). We have used $5 \%$ and $95 \%$ quantiles as climate thresholds for each species (Table $\mathbf{1}$ is an example for Abies nephrolepis).

\section{Plants Assigned Groups and Bioclimatic Clustering}

We defined four groups of plants with different morphology and phenology based on the Illustrated Flora of Higher Plants in China (Institute of Botany of Chinese Academy of Sciences, $1985 \&$ \& 1987) according to their height (trees vs. shrubs/lianas vs. herbs) and leaf shape (broadleaved vs. conifer trees/shrubs). Then we have clustered the plant taxa in each group using 73 climatic
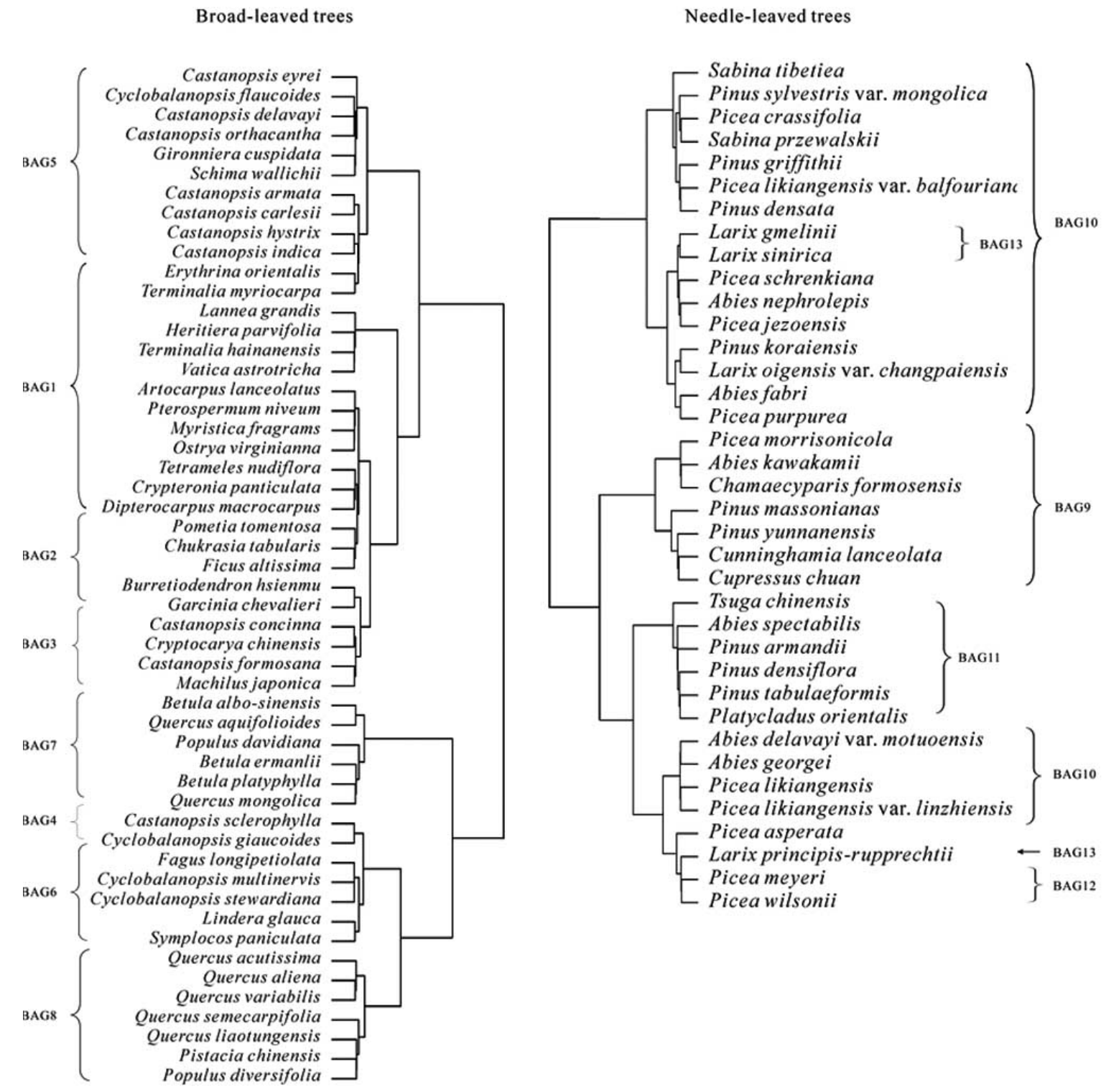

Fig. (2). Dendrogram summarizing the hierarchical cluster analysis performed on a dataset of 73 climatic variables (12 months $\times 6$ variables + GDD5) and the occurrence of 52 broadleaved species (left hand side) and 37 conifers (right hand side). 
Table 1. Example of Relationship between Abies nephrolepis Distributions and Eight Climatic Variables

\begin{tabular}{|c|c|c|c|c|c|c|c|c|}
\hline \multirow{2}{*}{ Quantile } & \multicolumn{9}{|c|}{ Climatic Variables } \\
\cline { 2 - 9 } & TCO & TWA & MAT & PCO & PWA & MAP & GDD5 & RHU \\
\hline \hline 0 & -31.0 & 14.6 & -7.0 & 3.3 & 99.5 & 447.4 & 815.7 & 64.4 \\
\hline 5 & -29.9 & 15.1 & -6.1 & 3.4 & 107.4 & 470.1 & 892.1 & 64.5 \\
\hline 10 & -29.7 & 15.4 & -5.8 & 3.4 & 113.5 & 497.4 & 943.0 & 64.6 \\
\hline 25 & -24.7 & 16.7 & -1.3 & 3.8 & 128.1 & 566.9 & 1227.1 & 65.2 \\
\hline 50 & -21.7 & 18.1 & -0.4 & 4.3 & 144.1 & 638.8 & 1483.2 & 67.0 \\
\hline 75 & -17.7 & 19.4 & 2.2 & 6.7 & 168.4 & 673.0 & 1586.7 & 68.4 \\
\hline 90 & -16.2 & 19.9 & 2.7 & 7.6 & 176.3 & 712.7 & 1720.3 & 69.6 \\
\hline 95 & -15.6 & 20.2 & 3.2 & 8.26 & 179.9 & 741.8 & 1803.6 & 69.9 \\
\hline 100 & -13.8 & 21.4 & 4.1 & 9.7 & 186.2 & 799.6 & 1966.8 & 70.5 \\
\hline
\end{tabular}

TCO: Temperature of the coldest month $\left({ }^{\circ} \mathrm{C}\right)$, TWA: Temperature of the warmest month $\left({ }^{\circ} \mathrm{C}\right)$; MAT: Mean annual temperature $\left({ }^{\circ} \mathrm{C}\right)$; PCO: Precipitation during the coldest month (mm); PWA: Precipitation during the warmest month (mm); GDD5: Growing degree days above $5^{\circ} \mathrm{C}\left({ }^{\circ} \mathrm{C}-\right.$ day); RHU: Relative humidity index $(\%)$

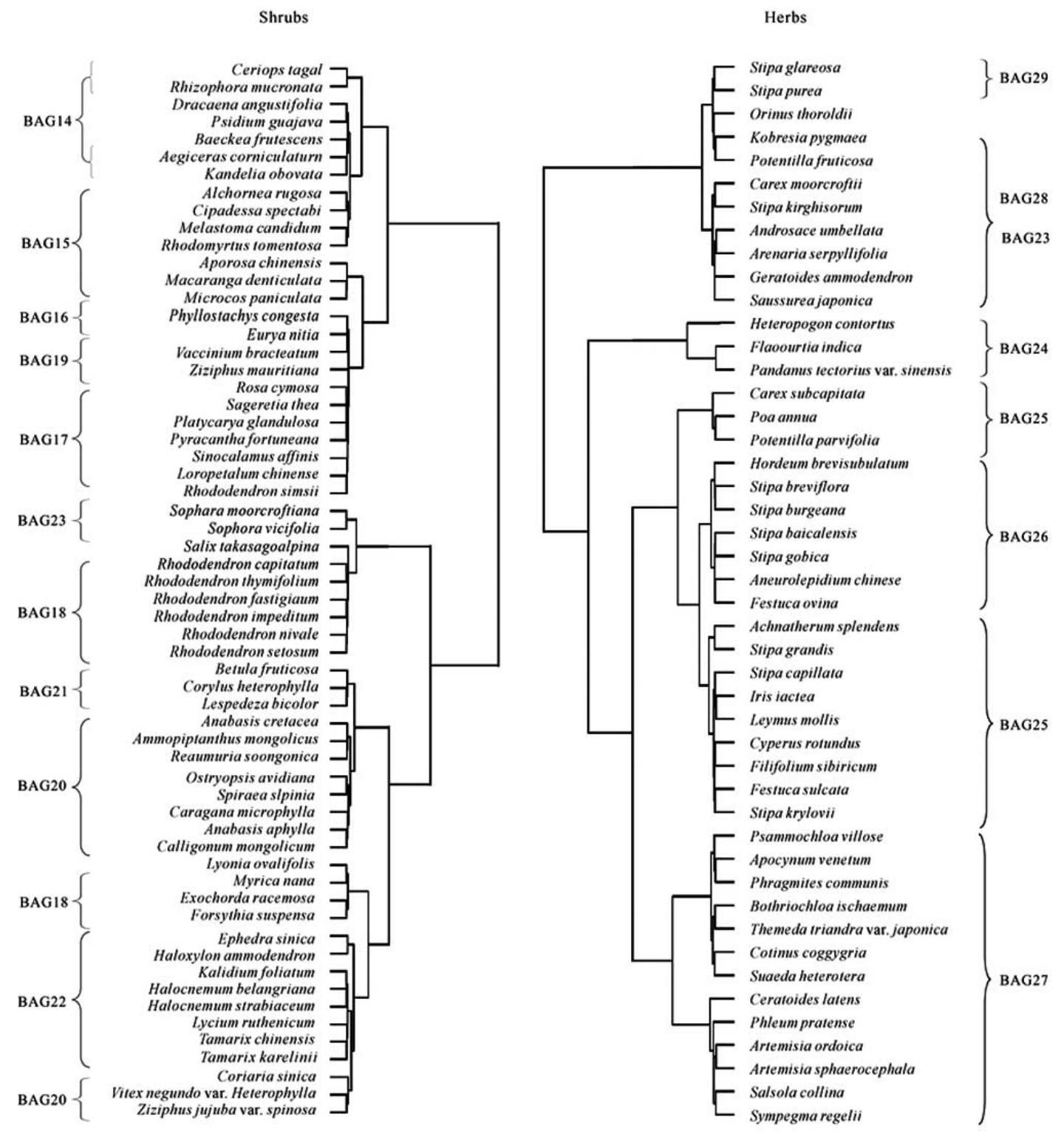

Fig. (3). Dendrogram summarizing the hierarchical cluster analysis performed on a dataset of 73 climatic variables (12 months $\times 6$ variables + GDD5) and the occurrence of 63 shrubs (left hand side) and 44 herbs (right hand side). 
variables (12 months $\times 6$ variables + GDD5) using a hierarchical clustering based on Euclidean distances and Ward's minimum variance method (Ward 1963, R Development Core Team 2007). The hierarchical relationships between clusters are illustrated by dendrograms (Figs. 2, 3). The distance matrix was then used for a hierarchical analysis to identify clusters of taxa defined as bioclimatic affinity groups (BAGs). This approach has been successfully developed and tested in Europe (Laurent et al. 2004, 2008).

The advantage of the BAG method is that (1) it provides a more detailed classification of vegetation and, hence, is more relevant at the continental or sub-continental scale compared to other methods which were established mostly for the global scale, and (2) the species are grouped according to their similarities in terms of their dependence to climatic variables (bioclimatic affinity), and thus probably in terms of their response to climate change. In some way, the first step of the BAG method is exactly the same as in PFT modeling, since plant species are first grouped according to plant functional properties such as leaf type (needleleaf, broadleaf), leaf phenology (deciduous, evergreen), and belonging to vegetation storey (herbs, shrubs, trees). Other characteristics may be used, depending on the model purposes, such as shade tolerance and seed dispersal abilities. Each of these broad classes is then subdivided according to bioclimatic affinity using a cluster analysis. The resulting classification ensures that the grouped plants are climatically similar, and so can be used as the smallest entity to be represented in the model.

\section{Vegetation Model}

CARAIB (CARbon Assimilation in the Biosphere) Dynamic Vegetation Model is a mechanistic model that simulates the carbon cycle in the terrestrial biosphere (Hubert et al. 1998, Otto et al. 2002). It computes the carbon stored in vegetation and its flow between vegetation, the atmosphere and soil (Warnant et al. 1994, Hubert et al. 1998, Warnant 1999, Otto et al. 2002, Laurent et al. 2004, 2008).

Table 2. Climatic Tolerances (Tmin, Tmax, SWmax_germ) and requirements (GDD5, Tmax_germ) of 29 BAGs

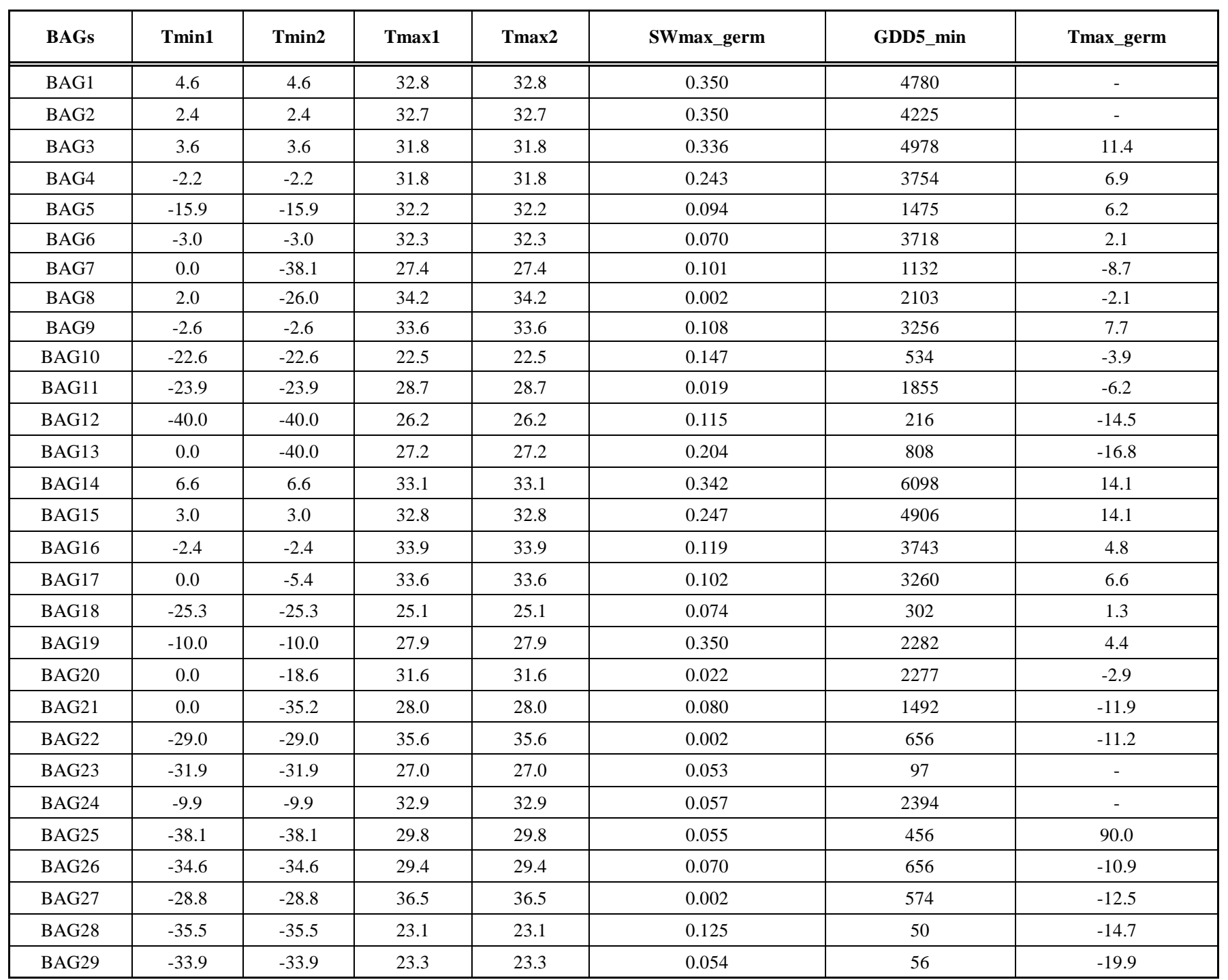

Tmin is the $1 \%$ quantile of the absolute minimum daily mean temperature $\left({ }^{\circ} \mathrm{C}\right)$, Tmax is the $1 \%$ quantile of the absolute maximum daily mean temperature $\left({ }^{\circ} \mathrm{C}\right)$ (not used by the model), Tmax _germ is the $1 \%$ quantile of the coldest monthly mean temperature and SWmax germ is the $1 \%$ quantile of soil water content below which soil water stress occurs, GDD5 is the growing degree-days based on a threshold temperature of $5{ }^{\circ} \mathrm{C}$. Soil water contents are expressed as available soil water relative to field capacity, $\mathrm{SW}=(\mathrm{WA}-\mathrm{WP}) /(\mathrm{FC}-\mathrm{WP})$ where WA, FC and WP are soil water content, field capacity and wilting point in mm. 
CARAIB does not simulate actual but potential ranges which correspond to areas where climatic conditions theoretically allow the presence of a plant species. By potential distribution we mean that the simulation suggests that a BAG may "potentially" occur in an area where it is not observed today. The mismatch between the observed and potential (simulated) distributions today may be related to any other reason than the climate variables used by the model. In the model, BAGs are the smallest plant entity. Consequently, as PFTs, they respond as a unit to climate change and as a result models cannot capture the change in species composition and abundance of a given BAG that may occur through time in the real world.

As input, CARAIB requires mean daily temperatures, the amplitude of temperature diurnal variation, relative sunshine, relative humidity of the air, horizontal wind speed, precipitation, and soil texture. The hydrological sub-model (Hubert et al. 1998) computes water availability in the soil, actual evapotranspiration and runoff, air temperature, soil humidity, wind speed and solar radiation on a daily basis. The same climatic dataset is used for calibrating the climatedependent parameters of the model and for running it. This may be seen as circular. Actually, this means that the simulation is only a model test, but not a real validation. This situation is similar to that found in climate modeling, where models are also fitted to reproduce present-day climate and, hence, where good behaviour of the model for the present is not a real validation of the model. The only way to get a more independent validation is to turn to past climates, but then reliable and precise data on past climates are needed. The situation is exactly the same here for vegetation modeling where we would have to make simulations for past climates or eventually over other nearby countries where similar vegetation is growing. For China vegetation, the necessary palaeodata are not available right now, but we hope to go in this direction in future studies.

CARAIB simulates BAGs which are defined by a set of parameters describing their climate tolerances (Table 2). We deduced the climatic boundaries of 29 BAGs using quantilefunctions and chose the 0.01 and 0.99 quantiles as the lowest and the highest limits, respectively (Table 2 ). In mountain areas, this method can produce poor results for temperaturerelated parameters (Tmin, GDD5, Tmax_germ; see Table 2), because elevation can vary by several hundreds or even thousands of meters within a single $10^{\prime} \times 10^{\prime}$ grid cell over which species presence and climatology are provided, implying huge variations of air temperature within the same grid cell. The problem is particularly acute in the Himalayas. Consequently a correction was made on temperatures, using GTOPO30 digital elevation model at 30"x30" resolution (http://www1.gsi.go.jp/geowww/globalmap-gsi/gtopo30/ gtopo30.html) and assuming an atmospheric lapse rate of 6.5 ${ }^{\circ} \mathrm{C} / \mathrm{km}$. For instance, to calculate the Tmin or GDD5 thresholds of the species, it was assumed that the species was present in the "warmest" part of the grid cell, i.e., at lower elevation below the $1 \%$ elevation quantile. For Tmax_germ (controlling the warmest front of the species), it was assumed that the species was present on the coldest portion, above the $99 \%$ elevation quantile. A problem also appeared for BAG 13 "Cool temperate conifer deciduous trees", which is composed of Larix species. Larix does not reach its coldest limit in China and so the Tmin and GDD5 thresholds

Table 3. Biome Assignment Scheme. GDD5 is the Growing Degree-Days Based on a Threshold Temperature of $5{ }^{\circ} \mathrm{C}$

\begin{tabular}{|c|c|c|c|c|c|c|}
\hline Biome & GDD5 $/{ }^{\circ} \mathrm{C}$ & NPPtot & LAItot & $\mathbf{R}$ & LAItrees & BAGs \\
\hline Cool temperate mixed forest & $>350$ & $\neq 0$ & $\geq 0.4$ & $\leq 0.5$ & $\geq 1.5$ & $7,10,12,13$ \\
\hline Temperate broadleaved deciduous forest & $>350$ & $\neq 0$ & $\geq 0.4$ & $\leq 0.5$ & $\geq 1.5$ & 7,8 \\
\hline Warm temperate mixed forest & $>350$ & $\neq 0$ & $\geq 0.4$ & $\leq 0.5$ & $\geq 1.5$ & 5,8 \\
\hline Warm temperate broadleaved evergreen forest & $>350$ & $\neq 0$ & $\geq 0.4$ & $\leq 0.5$ & $\geq 1.5$ & 5 \\
\hline Sub-tropical forest & $>350$ & $\neq 0$ & $\geq 0.4$ & $\leq 0.5$ & $\geq 1.5$ & $3,4,6,9$ \\
\hline Tropical seasonal forest & $>350$ & $\neq 0$ & $\geq 0.4$ & $\leq 0.5$ & $\geq 1.5$ & 1,2 \\
\hline Tropical rainforest & $>350$ & $\neq 0$ & $\geq 0.4$ & $\leq 0.5$ & $\geq 1.5$ & - \\
\hline Cold temperate/boreal open woodland & $>350$ & $\neq 0$ & $\geq 0.4$ & $\leq 0.5$ & $\geq 0.5$ & $7,10,11,12,13$ \\
\hline Shrubland & $>350$ & $\neq 0$ & $\geq 0.4$ & $>0.5$ & $\geq 0.5$ & 14,23 \\
\hline Semi-desert & $>350$ & $\neq 0$ & $<0.4$ & & & \\
\hline Desert & $>350$ & $=0$ & & & & \\
\hline Tundra & {$[50,350]$} & & & & & \\
\hline Ice or polar desert & $<50$ & & & & & \\
\hline
\end{tabular}

NPPtot and LAItot are the sum of the net primary productivity (NPP) and leaf area index (LAI) of each BAG weighted by their respective cover fraction. R is the ratio between the total NPP of the sixteen grass/shurb BAGs (NPP grasses) and the total NPP of the thirteen tree BAGs (NPP trees). BAGs are numbered from 1 to 29 (Table 2 ) 
of BAG 13 were significantly overestimated. Consequently, the full distribution of Larix gmelinii in China, Mongolia and Siberia (Semerikov and Lascoux 1999) was digitized and used to calculate Tmin and GDD5 for BAG 13.

Biomes are determined according to the classification scheme described in Table 3 . The ice or polar tundra biomes are assigned based on climatic criteria, i.e., GDD5, as defined initially in dynamic vegetation models (BIOME, CARAIB and IBIS) (BIOME: Prentice et al. 1992, CARAIB: Warnant et al. 1994, IBIS: Foley et al. 1996). The value of $350{ }^{\circ} \mathrm{C}$-day for the tundra biome is the same as in the BIOME3 and IBIS models, and the value of $50{ }^{\circ} \mathrm{C}$-day for the limit of ice has been adjusted to reproduce two potential natural global vegetation maps (Melillo et al. 1993, Matthews 1983, Otte 2002). The other biomes are assigned on the basis of two outputs of the CARAIB model, i.e., the LAI and the NPP of each BAG and their occurrence, or of parameters directly derived from these two variables.

\section{RESULTS}

Twenty-nine BAGs were derived from 196 dominant species in the Chinese vegetation (Tables 2 to 7). These BAGs include six evergreen and two summer-green broadleaved trees, four evergreen conifer and one summergreen conifer tree, five evergreen broadleaved shrubs, five summer-green broadleaved shrubs, and six herbaceous BAGs. Broadly, tree groups are distributed in eastern China and the Tibetan plateau (Fig. 4) where annual precipitation is high. Shrub groups are mainly distributed in northwestern and mountains in subtropical region. Herbaceous groups are distributed in northern China and the Tibetan plateau. As a general statement for all plant groups, the model simulated ranges correspond to potential distributions which cover larger and spatially more continuous areas than the observed ones. Today, the natural vegetation is being strongly impacted by different human activities (cultivation, deforestation, introduction of fast growing species, grazing ...) (Fig. 1).

\section{Bioclimatic Affinity Groups of Trees}

Fifty-two broadleaved species are clustered into 8 BAGs (Fig. 2, Table 4). This includes two tropical BAGs (BAG1: tropical rainforest and $\mathrm{BAG} 2$ : tropical seasonal forest), 4 subtropical BAGs (BAG3: South subtropical broadleaved evergreen trees, BAG4: mid-subtropical broadleaved evergreen trees, BAG5: subtropical mountain broadleaved evergreen trees, BAG6: north subtropical evergreen broadleaved trees) and two temperate BAGs (BAG7: Temperate broadleaved deciduous trees, BAG8: Warm temperate broadleaved deciduous trees). We have assigned some taxa to more than one BAG according to their geographical distribution. For instance, although Terminalia hainensis is statistically clustered within the tropical rainforest (BAG1) we have included it also in the tropical seasonal forest (BAG2) because we have observed in the field that it sometimes dominates the latter BAG. Gironniera cuspidata and Schima wallichii are clustered within the subtropical mountain broadleaved evergreen trees but we assigned them also to the tropical seasonal forest (BAG2)

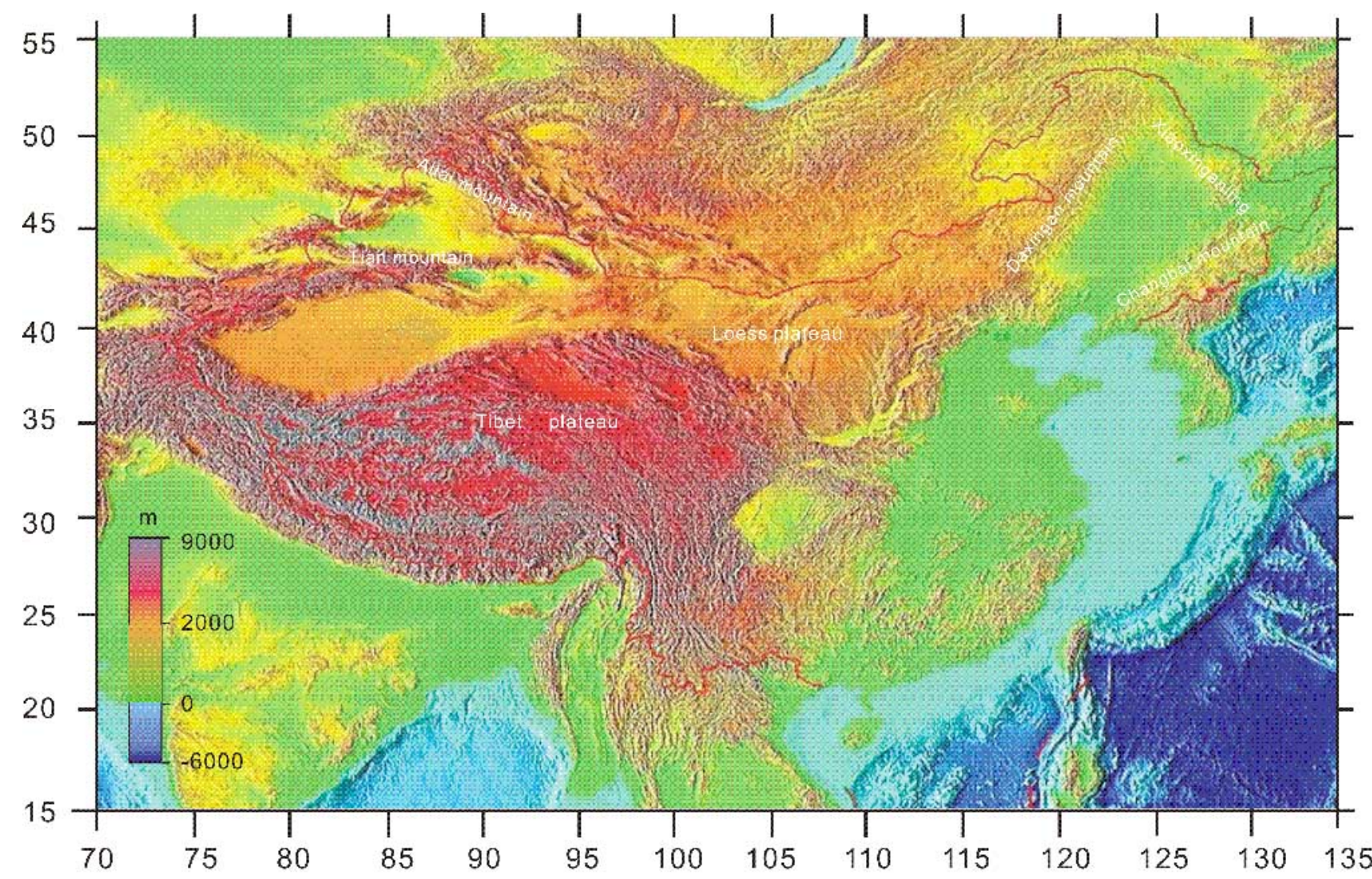

Fig. (4). Topography map of China showing the main areas disccussed in this work. 
Simulated distribution (BAG 1)

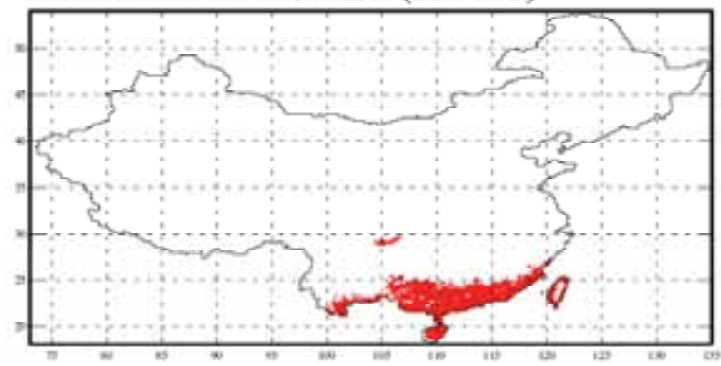

Simulated distribution (BAG 2)

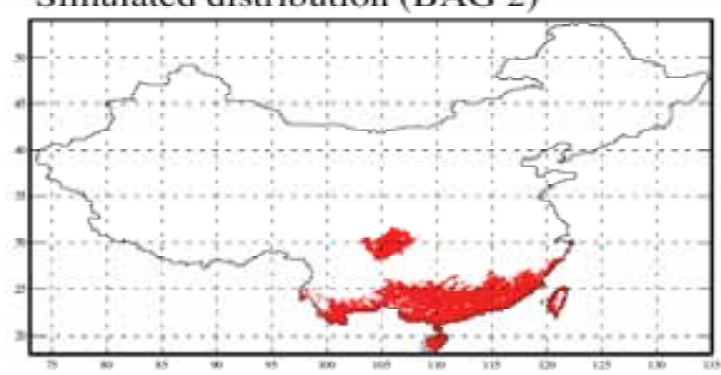

Simulated distribution (BAG 3)

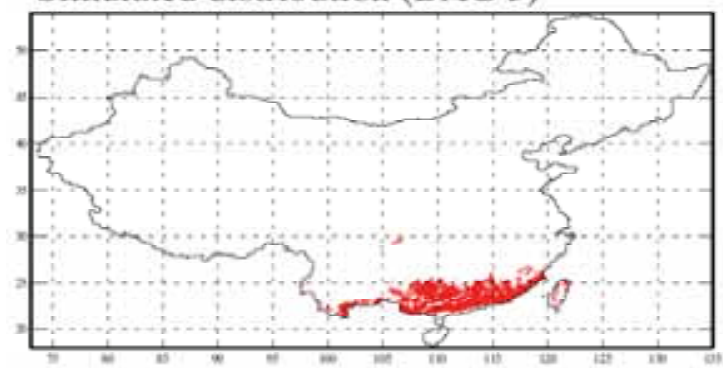

Simulated distribution (BAG 4)

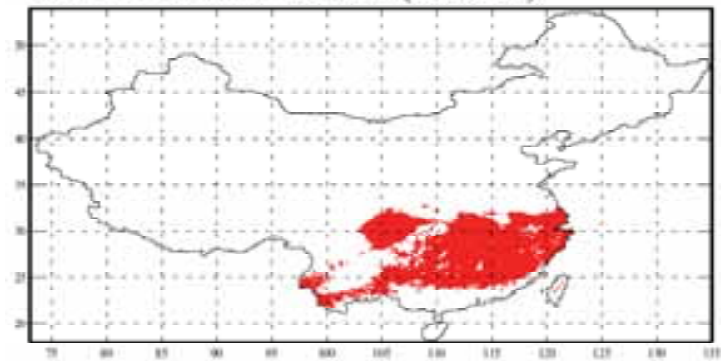

Simulated distribution (BAG 5)

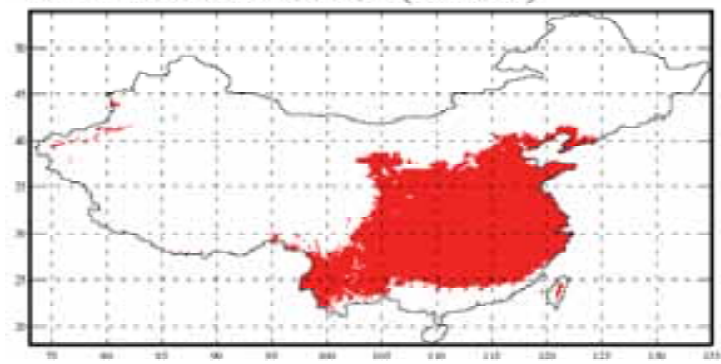

Observed distribution (BAG 1)

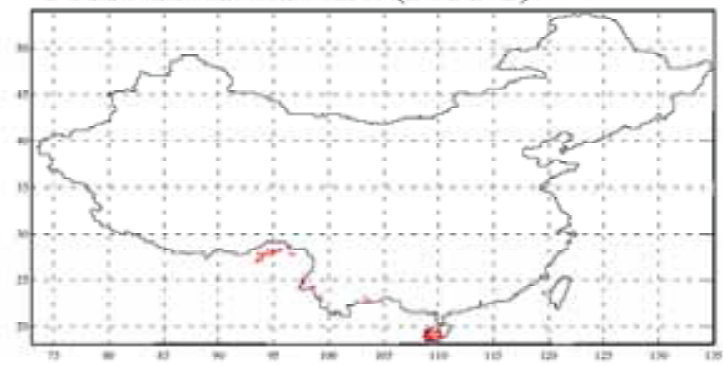

Observed distribution (BAG 2)

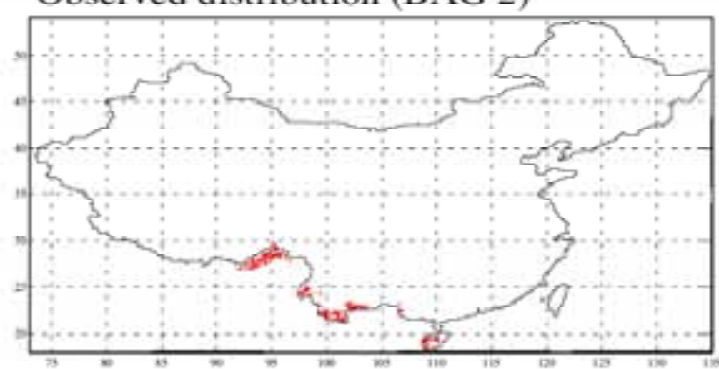

Observed distribution (BAG 3)

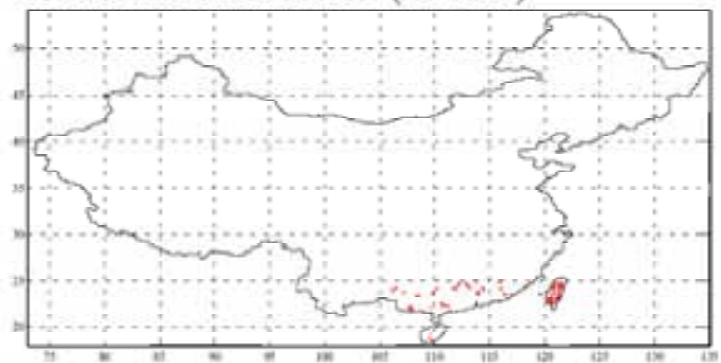

Observed distribution (BAG 4)

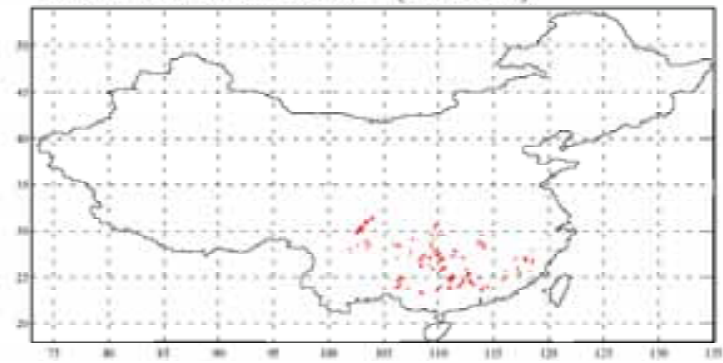

Observed distribution (BAG 5)

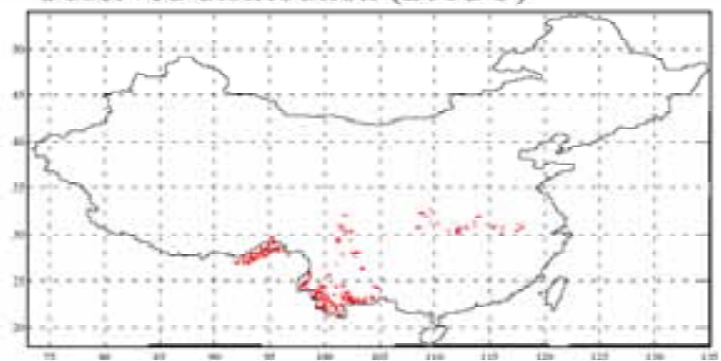

Fig. (5). Comparison of distributions between simulated and observed broadleaved tree BAGs.

because of their occurrence in this ecosystem. Fagus longipetiolata, a deciduous tree, is statistically clustered in a subtropical evergreen broadleaved group (BAG6) trees) and that is coherent with our field observations. 
Table 4. Bioclimatic Affinity Groups (BAGs) of Broadleaved Trees

\begin{tabular}{|c|c|}
\hline BAG1: Tropical raingreen trees & $\begin{array}{c}\text { Artocarpus lanceolatus, Crypteronia panticulata, Dipterocarpus macrocarpus, Erythrina } \\
\text { orientalis, Myristica fragrams, Ostrya virginiana, Pometia tomentos, Pterospermum niveum, } \\
\text { Heritiera parvifolia, Terminalia myriocarp, Tetrameles nudiflor, Vatica astrotricha }\end{array}$ \\
\hline BAG2: Tropical seasonal raingreen trees & $\begin{array}{c}\text { Burretiodendron hsienmu, Chukrasia tabularis, Ficus altissima, Garcinia chevalieri, Gironniera } \\
\text { cuspidata, Lannea grandis, Schima wallichii, Terminalia hainanensis }\end{array}$ \\
\hline BAG4: Mid-subtropical broadleaved evergreen trees & Castanopsis eyrie, C. sclerophylla, Cyclobalanopsis giaucoides \\
\hline $\begin{array}{l}\text { BAG5: Subtropical mountain broadleaved evergreen } \\
\text { trees }\end{array}$ & $\begin{array}{l}\text { Castanopsis delavayi, C. hystrix, C. indica, C. orthacantha, Cyclobalanopsis flaucoides, } \\
\text { Lindera glauca, Quercus aquifolioides, Q. semecarpifolia, Gironniera cuspidat, Schima wallichii }\end{array}$ \\
\hline BAG6: North subtropical evergreen broadleaved trees & Cyclobalanopsis multinervis, C. stewardiana, Fagus longipetiolata, Symplocos paniculata \\
\hline
\end{tabular}

The simulated range of BAG8 agrees rather poorly (kcoef $=0.35$ ) with the observed distribution in the western region because of the presence of ground water in the desert which allows the persistence of Populus diversifolia in this area.

In the conifer group, 37 conifer species are clustered within 6 groups (Fig. 2). Larix, a deciduous conifer species occurs in two groups but we assigned it to one group (BAG13) because it is the only cool temperate conifer deciduous element. Conifer species in the cold temperate zone are clustered into five groups (Table 5, Fig. 2). Abies delavayi var. motuoensis, A. georgei, P. likiangensis, $P$. likiangensis var. balfouriana are clustered in the group of subtropical alpine conifer evergreen trees (BAG12) in Tibet plateau. There are two groups that occur in the subtropical zone: subtropical mountain evergreen conifer trees (BAG9) and the subtropical alpine evergreen conifer trees (BAG10) (Fig. 6). BAG9 is distributed in south of China including Taiwan province, the simulated range is in good agreement with the observed one. The dominant species of BAG10 are quite different from those of BAG9 in terms of climatic thresholds. BAG 10 has a lower temperature in winter ($\left.22.6^{\circ} \mathrm{C}\right)$ and lower GDD5 $\left(534^{\circ} \mathrm{C}\right.$-days) than BAG9 that requires warmer temperature $\left(\mathrm{GDD} 5>3256^{\circ} \mathrm{C}\right.$-days). BAG10 are distributed mainly in eastern Tibetan Plateau, and the simulation shows that northern China is suitable for BAG10 (Fig. 6).

\section{Bioclimatic Affinity Groups of Shrubs}

In many global vegetation models, there are no PFTs assigned to shrubs, which instead are usually associated with either trees or herbs. In the present study, we have identified five evergreen broadleaved shrubs and five summer-green broadleaved shrubs, which include 63 species (Fig. 3, Table 6). Although the distribution of these shrub species is initially driven by climate, they are affected by human activity and soil conditions. For instance, Aegiceras corniculatum, Ceriops tagal, Kandelia obovata and Rhizophora mucronata are clustered with other species in BAG15, which occur along the seacoast in the subtropical zone due to human impacts on the primary forest. The simulated distributions of shrubs (Fig. 7, 8 and 9), except BAG18, 20, 21 and $23(\mathrm{kcoef}<0.30)$, correspond quite well to the observed ones (Table $\mathbf{8}$ ). The dominant species within BAG18 occur in the subtropical alpine region, where the climatic conditions are similar to the temperate zone in northern China.

Table 5. Bioclimatic Affinity Groups (BAGs) of Conifer Trees

\begin{tabular}{|c|c|}
\hline BAG & Plant species \\
\hline BAG9: Subtropical conifer evergreen trees & $\begin{array}{c}\text { Abies kawakamii, Cunninghamia lanceolata, Cupressus chuan, Picea morrisonicola, Pinus } \\
\text { massoniana, P. yunnanensis, Chamaecyparis formosensis, Tsuga chinensis }\end{array}$ \\
\hline BAG10: Subtropical alpine conifer evergreen trees & $\begin{array}{c}\text { Abies delavayi var. motuoensis, A. fabri, A. georgei, A. spectabilis, Picea asperata, P. } \\
\text { likiangensis, P. likiangensis var. balfouriana, P. likiangensis var. linzhiensis, P. purpurea, } \\
\text { Pinus densata, P. griffithii, Sabina tibetiea }\end{array}$ \\
\hline BAG11: Warm temperate conifer evergreen trees & Pinus armandii, $P$. densiflora, $P$. tabulaeformis, Platycladus orientalis \\
\hline BAG12: Cool temperate/Alp conifer evergreen trees & $\begin{array}{c}\text { Abies nephrolepis, Picea crassifolia, } P \text {. jezoensis, } P \text {. meyeri, } P \text {. schrenkiana, } P \text {. wilsonii, Pinus } \\
\text { koraiensis, } P \text {. sylvestris var. mongolica, Sabina przewalskii }\end{array}$ \\
\hline BAG13: Cool temperate conifer deciduous trees & Larix gmelinii, L. principis-rupprechtii, L. olgensis var. changpaiensis, L. Sinirica \\
\hline
\end{tabular}


Simulated distribution (BAG 6)

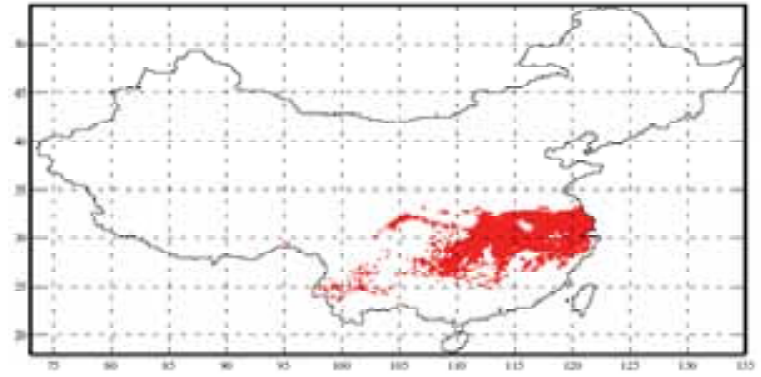

Simulated distribution (BAG 7)

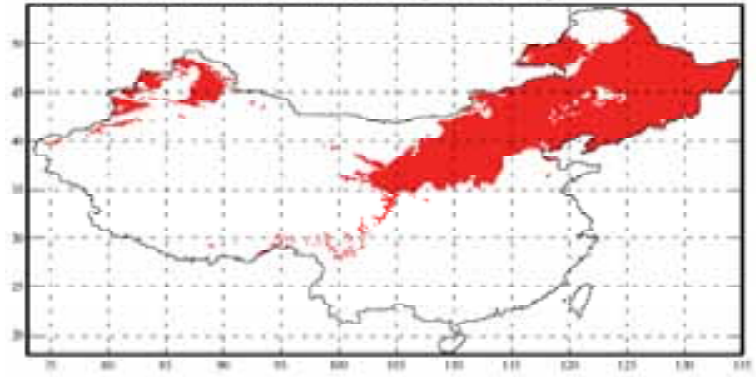

Simulated distribution (BAG 8)

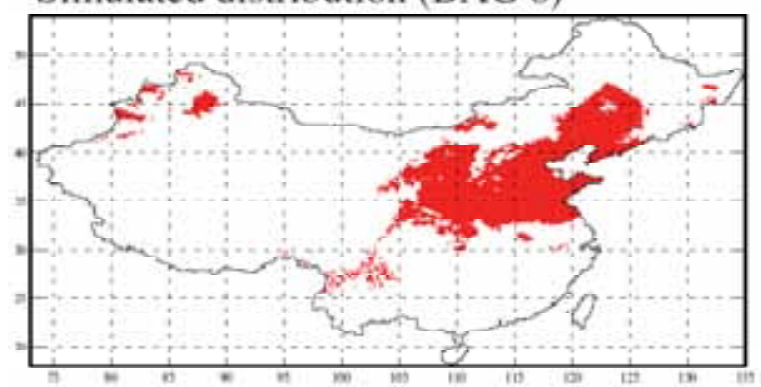

Simulated distribution (BAG 9)

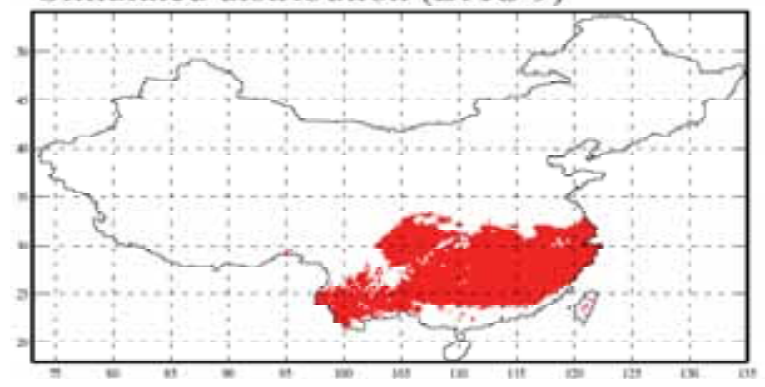

Simulated distribution (BAG 10)

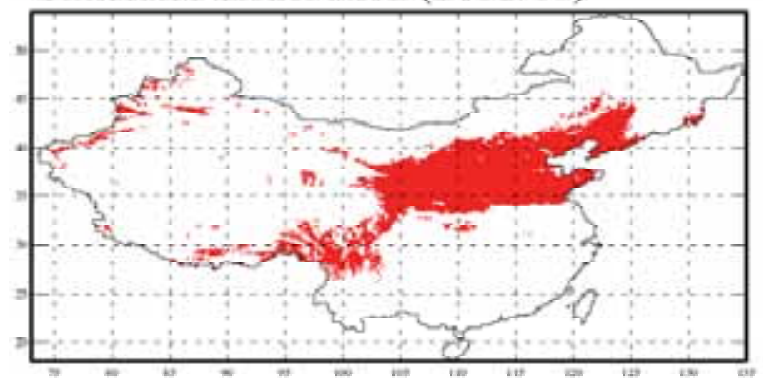

Observed distribution (BAG 6)

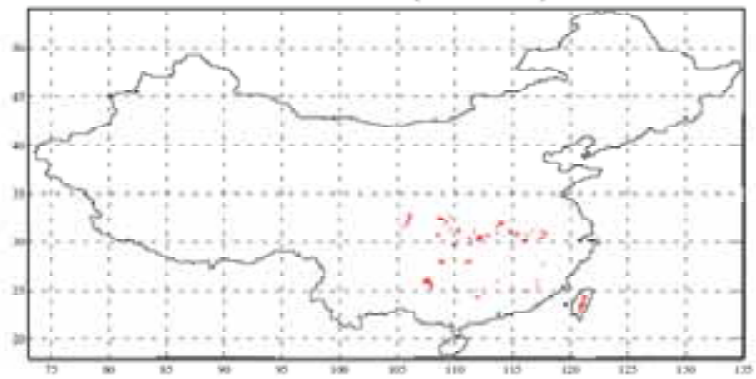

Observed distribution (BAG 7)

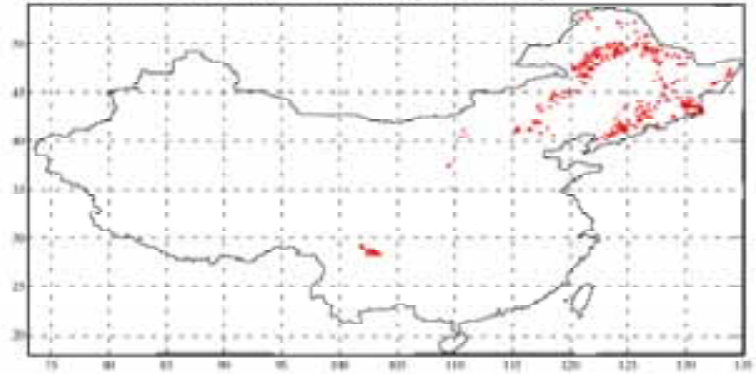

Observed distribution (BAG 8)

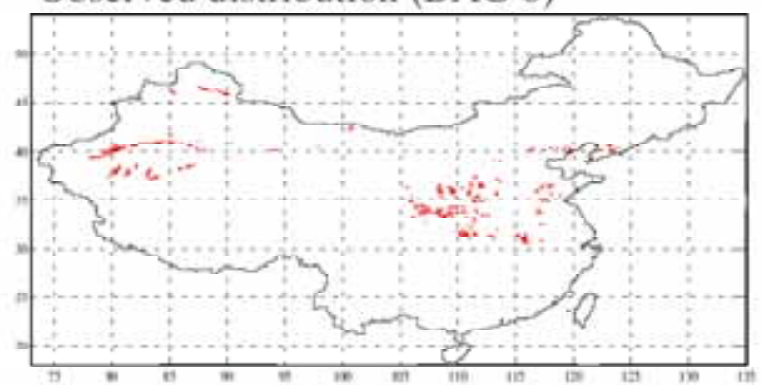

Observed distribution (BAG 9)

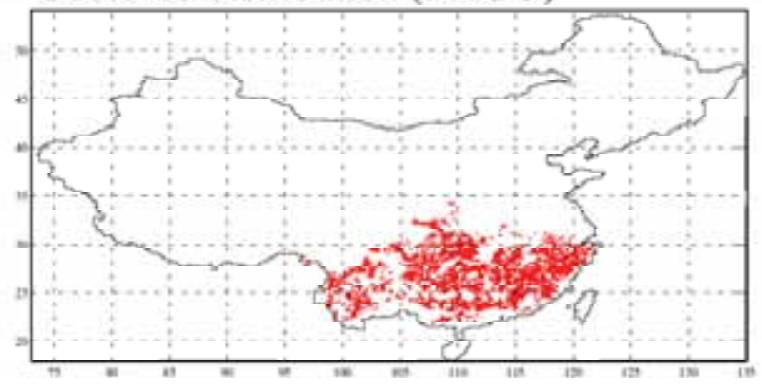

Observed distribution (BAG 10)

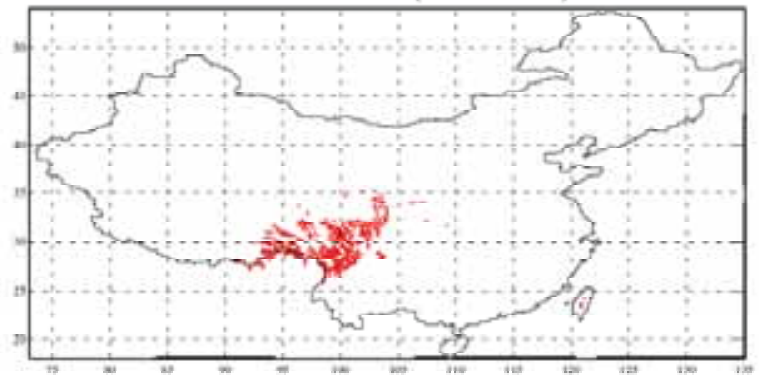

Fig. (6). Comparison of distributions between simulated and observed broadleaved tree BAGs (BAG 7 and 8) and conifer tree BAGs (BAG 9 and 10). 
Simulated distribution (BAG 11)

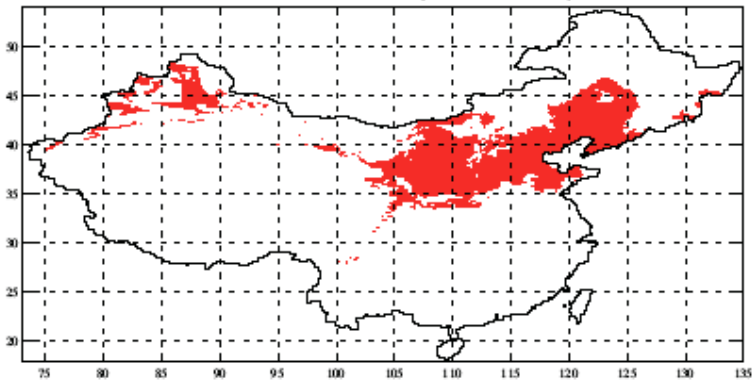

Simulated distribution (BAG 12)

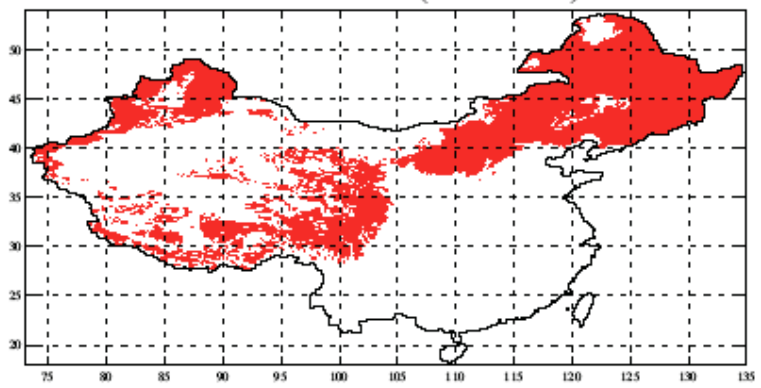

Simulated distribution (BAG 13)

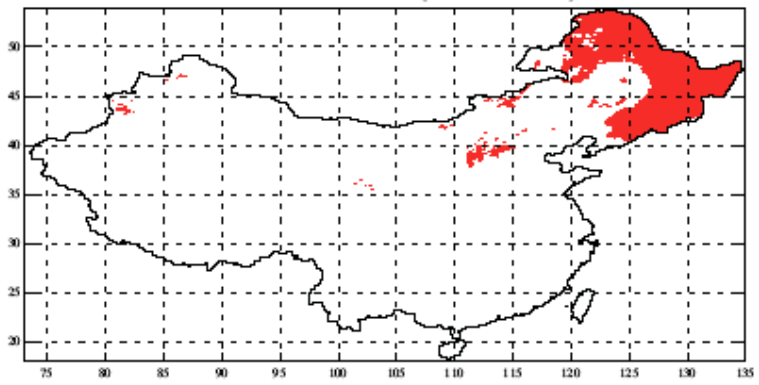

Simulated distribution (BAG 14)

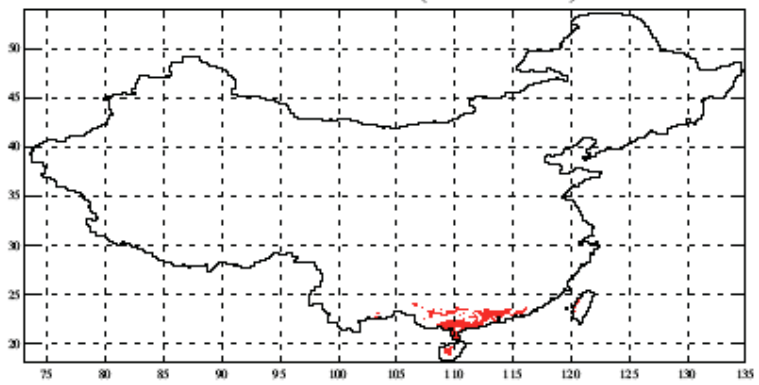

Simulated distribution (BAG 15)

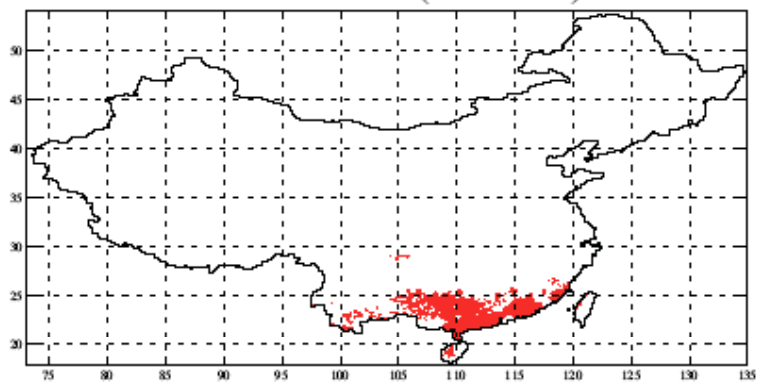

Observed distribution (BAG 11)

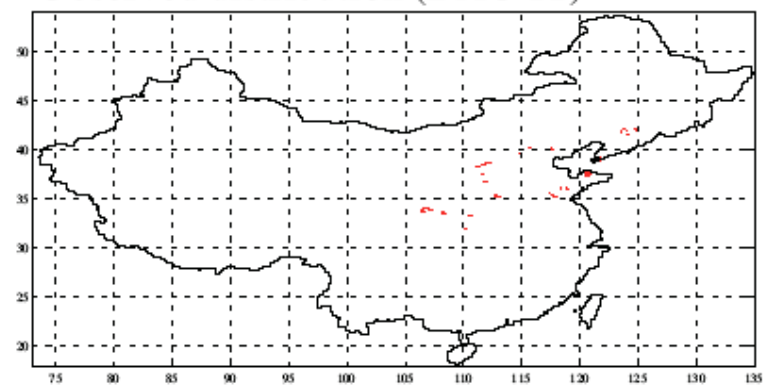

Observed distribution (BAG 12)

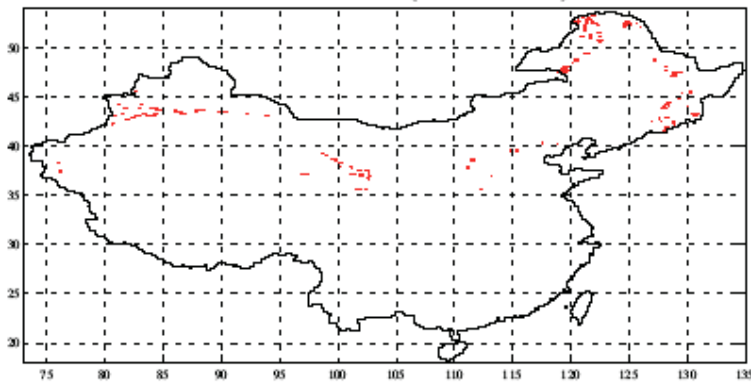

Observed distribution (BAG 13)

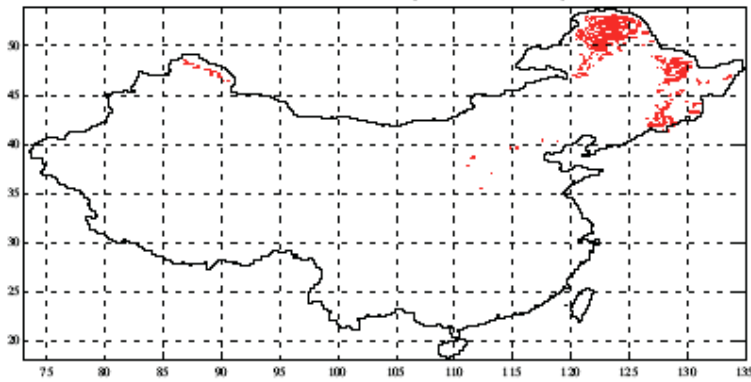

Observed distribution (BAG 14)

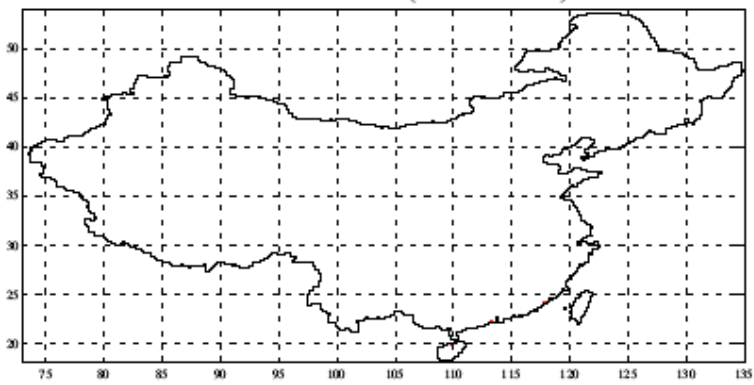

Observed distribution (BAG 15)

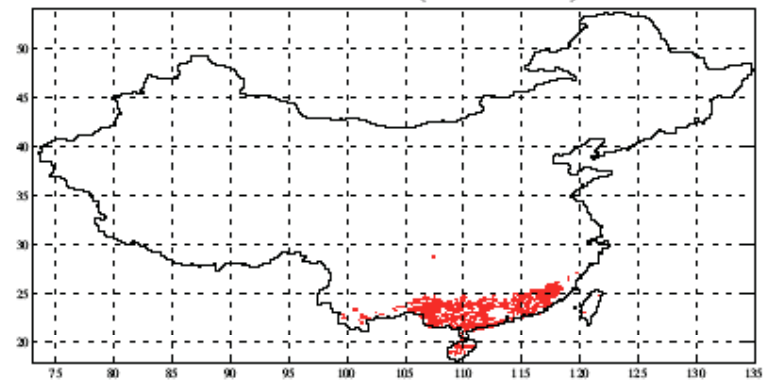

Fig. (7). Comparison of distributions between simulated and observed conifer tree BAGs (BAG 11 to 13) and shrub BAGs (BAG 14 and 15). 
Simulated distribution (BAG 16)

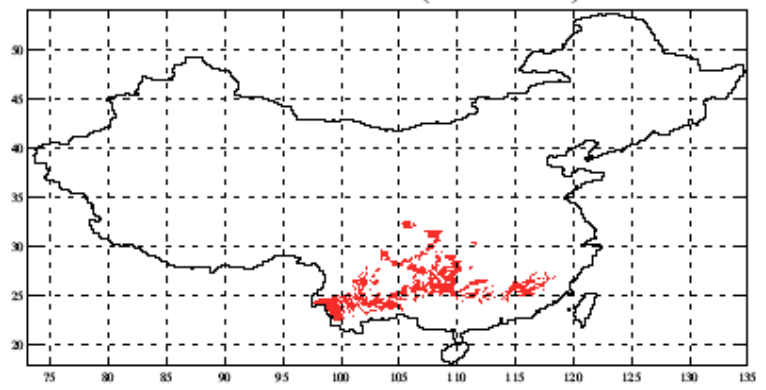

Simulated distribution (BAG 17)

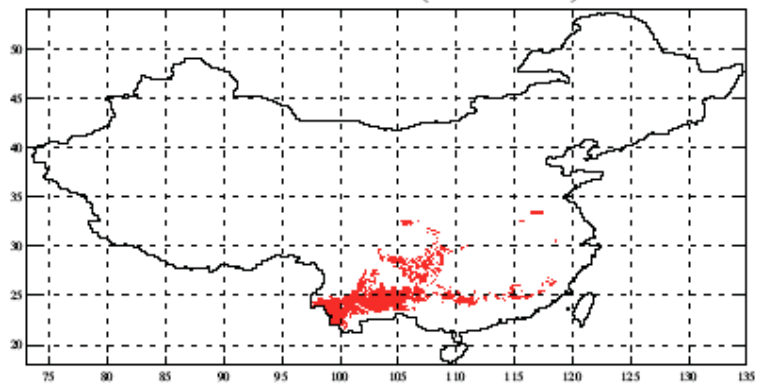

Simulated distribution (BAG 18)

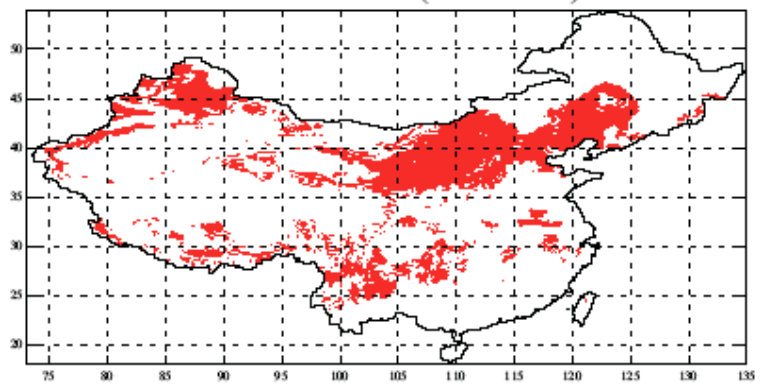

Simulated distribution (BAG 19)

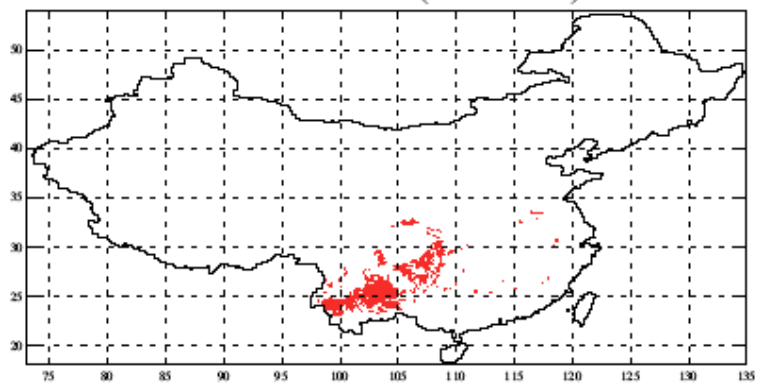

Simulated distribution (BAG 20)

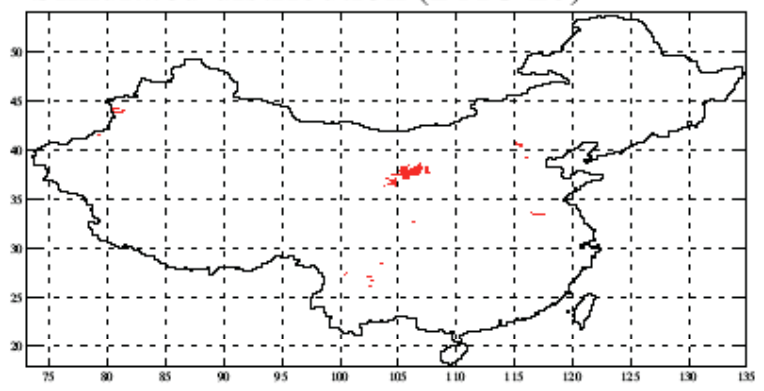

Observed distribution (BAG 16)

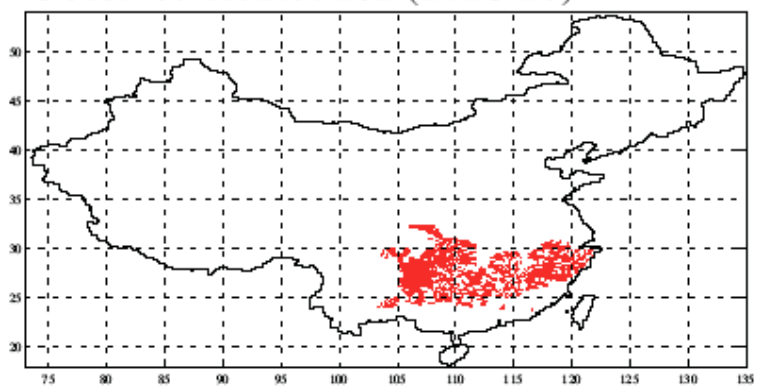

Observed distribution (BAG 17)

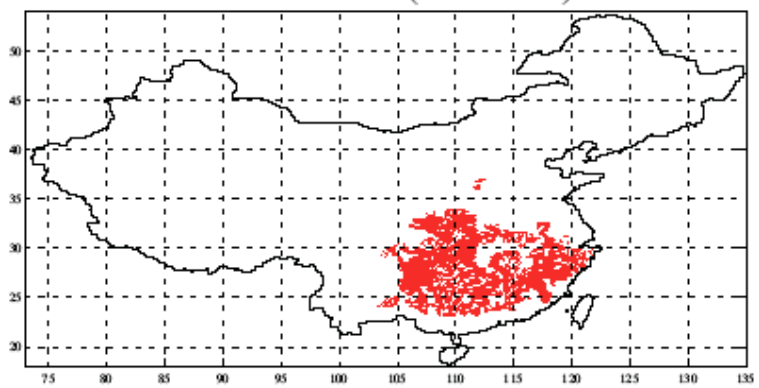

Observed distribution (BAG 18)

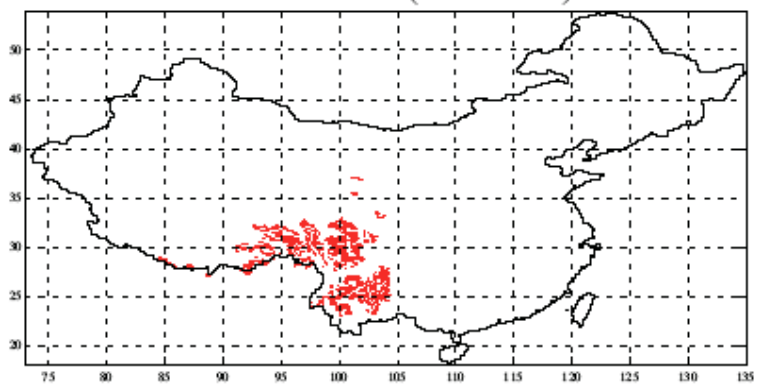

Observed distribution (BAG 19)

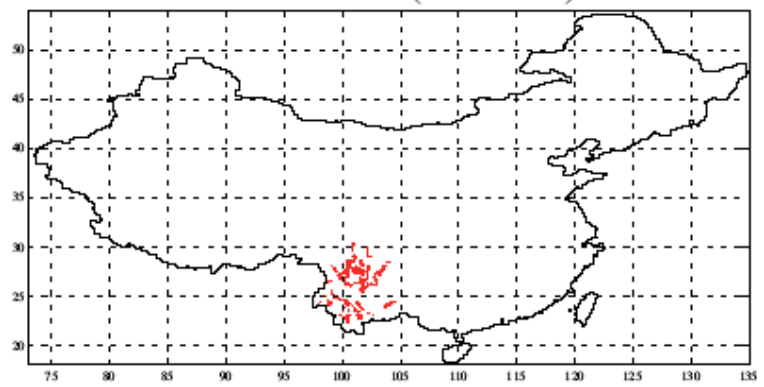

Observed distribution (BAG 20)

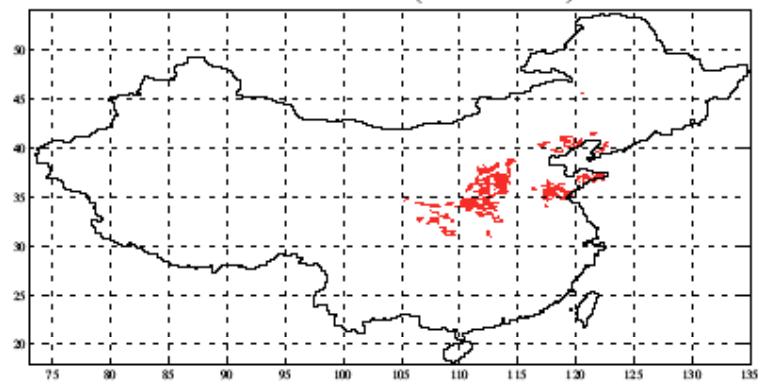

Fig. (8). Comparison of distributions between simulated and observed of shrub BAGs (BAG 16 to 20). 
Table 6. Bioclimatic Affinity Groups (BAGs) of Shrubs

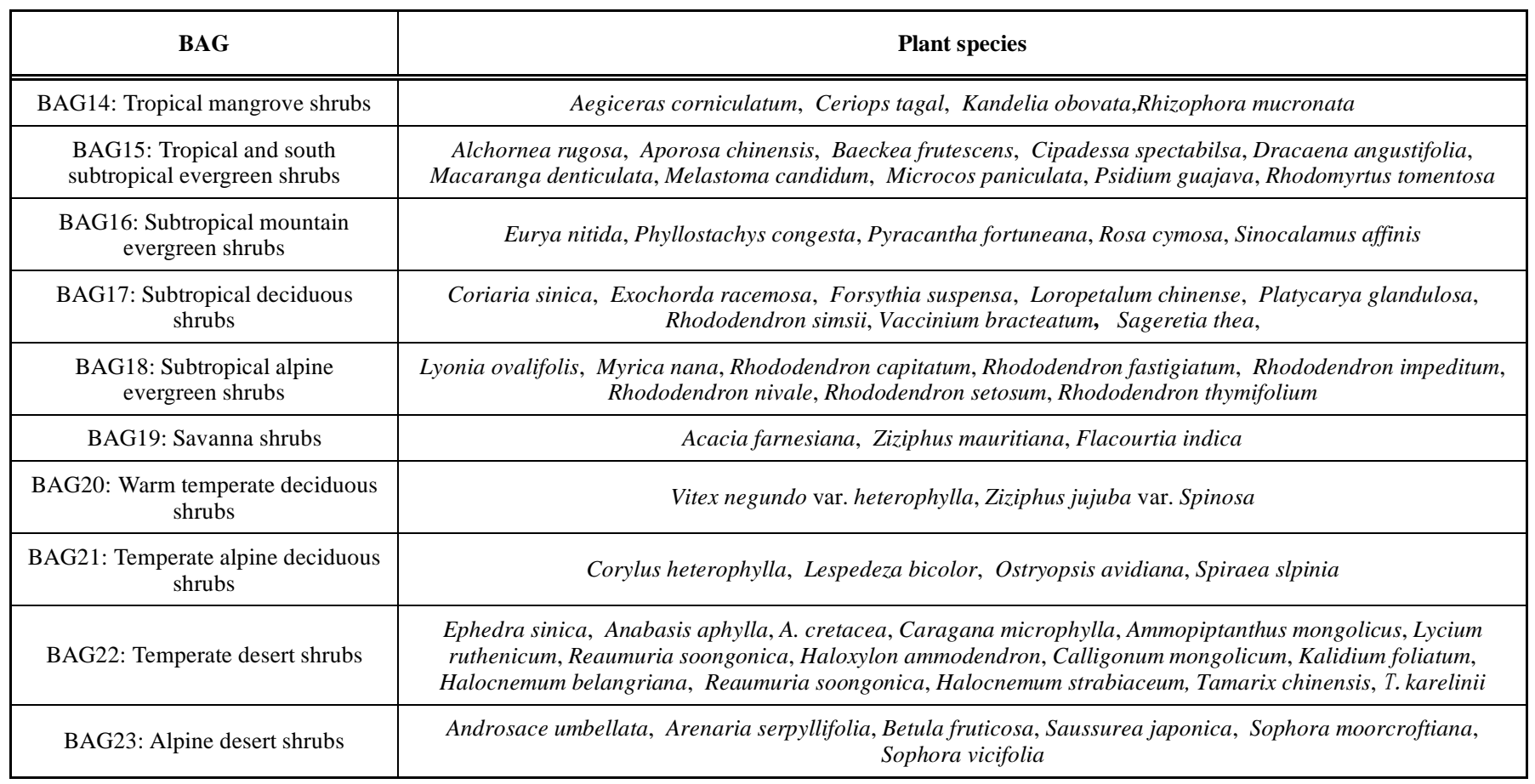

\section{Bioclimatic Affinity Groups of Herbs}

Six BAGs (24 to 29) are identified for herbs including 44 species which are mainly distributed in northwest China and Tibet plateau (Fig. 3, Table 7). BAG24 is composed of Heteropogon contortus, Pandanus tectorius var. sinensis, Flacourtia indica, which are the dominant species in savanna communities. This BAG is limited in the hot and dry valleys of southwest China. The simulated range is larger than the observed one as it includes the subtropical and temperate arid regions. BAG25 represents the meadow grassland in the ecotone between forest and grassland or alpine zone. The simulated range is also larger than the observed distribution. BAG26 and BAG27 (Fig. 10) represent the typical steppe and desert grassland, respectively. Within the alpine region, moisture determines whether a region supports meadow, steppe or alpine desert vegetation, and BAG28 and BAG29 (Fig. 10) are composed of many taxa such as Poaceae and Asteraceae in this region. Steppe and desert occur almost in all the western and northwestern areas (Fig. 1). The boundary between the herb and the shrub groups correspond to a mean annual precipitation around $500 \mathrm{~mm} / \mathrm{yr}$ except for the savanna grass group (BAG24).

\section{Biomes and BAGS Potential Distributions}

Based on bioclimatic criteria we have assigned BAGs to biomes (Table 3). The CARAIB model simulated a total of 19 biomes under current climate (Fig. 11). The boreal/ montane forest and cool temperate conifer forest all together occur in areas of the Changbai and Xiaoxingan mountains in north-eastern China (Fig. 4) where cool temperate mixed forest and temperate deciduous forests are dominant. The cold temperate/boreal open woodland and temperate broadleaved deciduous forests are simulated in north-eastern China. The warm temperate mixed forest is also simulated in

Table 7. Bioclimatic Affinity Groups (BAGs) of Herbs

\begin{tabular}{|c|c|}
\hline BAG & Plant species \\
\hline BAG24: Savanna steppe & Heteropogon contortus, Pandanus tectorius var. Sinensis, Flacourtia indica \\
\hline BAG25: Temperate meadow steppe & $\begin{array}{c}\text { Achnatherum splendens, Carex subcapitata, Cyperus rotundus, Festuca ovina, Filifolium sibiricum, Iris iactea, } \\
\text { Leymus mollis, Poa annua, Potentilla parvifolia, Stipa capillata, Stipa grandis, Stipa krylovii }\end{array}$ \\
\hline BAG26: Temperate steppe & $\begin{array}{c}\text { Aneurolepidium Chinese, Festuca sulcata, Hordeum brevisubulatum, Stipa baicalensis, S. breviflora, } S . \\
\text { bungeana, } S . \text { gobica }\end{array}$ \\
\hline $\begin{array}{l}\text { BAG27: Temperate semi-desert } \\
\text { steppe }\end{array}$ & $\begin{array}{c}\text { Apocynum venetum, Artemisia ordoica, A. sphaerocephala, Ceratoides lateens, Phleum pratense, Phragmites } \\
\text { communis, Psammochloa villose, Salsola collina, Sympegma regelii }\end{array}$ \\
\hline BAG28: Alpine meadow steppe & $\begin{array}{c}\text { Kobresia pygmaea, Potentilla fruticosa, Carex moorcroftii, Stipa kirghisorum, Androsace umbellata, Arenaria } \\
\text { serpyllifolia, Geratoides ammodendron, Saussurea japonica }\end{array}$ \\
\hline BAG29: Alpine desert steppe & Ceratoides lateens, Carex moorcroftii, Stipa glareosa, S. purea \\
\hline
\end{tabular}


Simulated distribution (BAG 21)

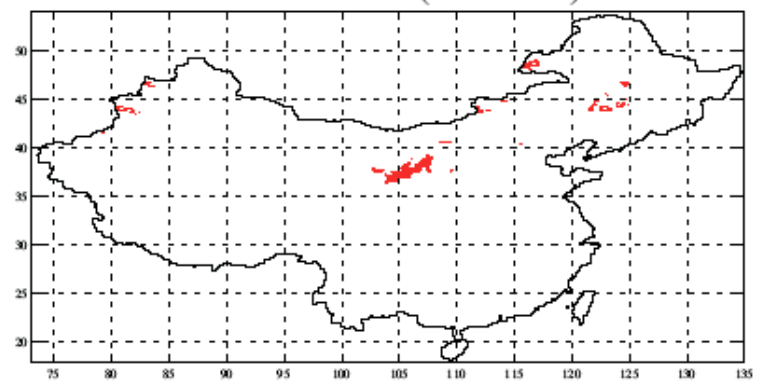

Simulated distribution (BAG 22)

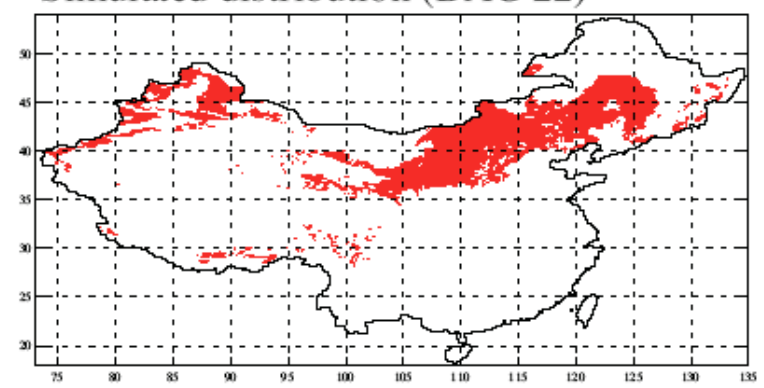

Simulated distribution (BAG 23)

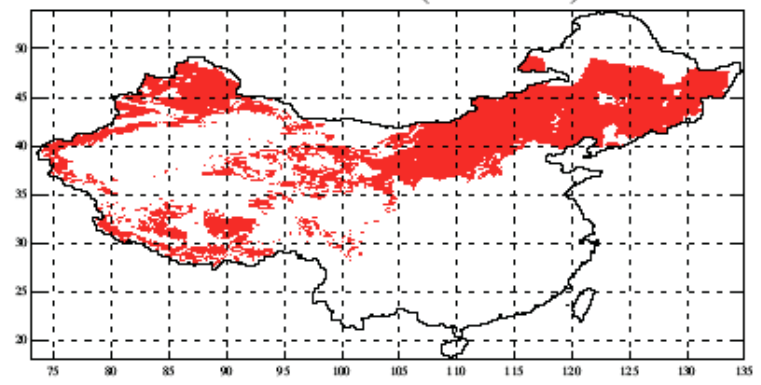

Simulated distribution (BAG 24)

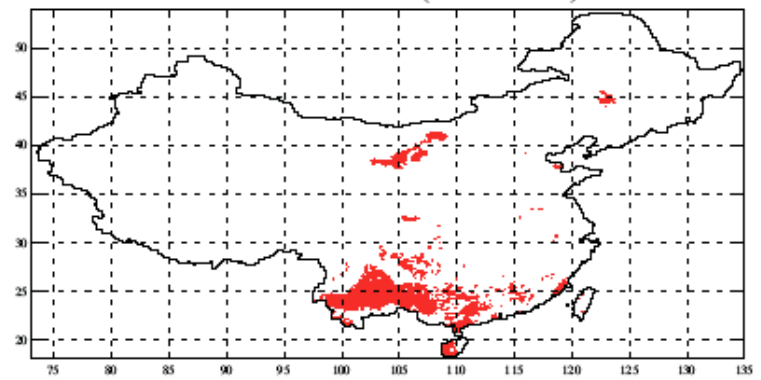

Simulated distribution (BAG 25)

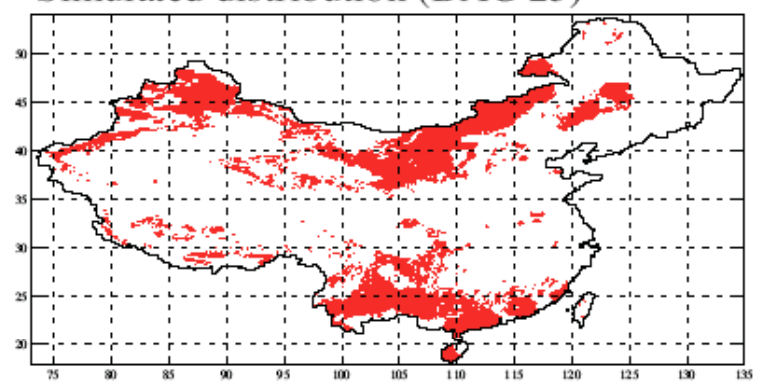

Observed distribution (BAG 21)

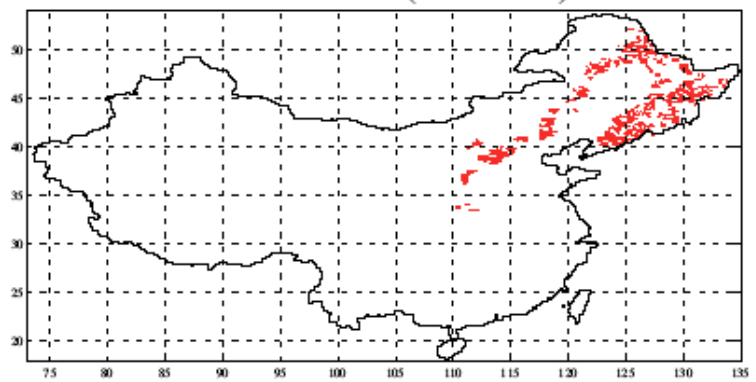

Observed distribution (BAG 22)

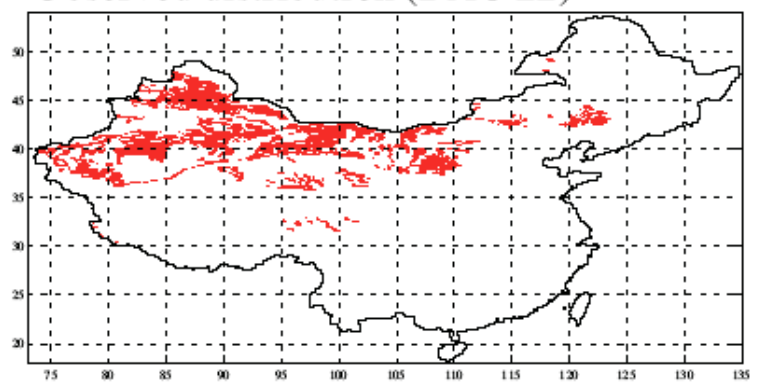

Observed distribution (BAG 23)

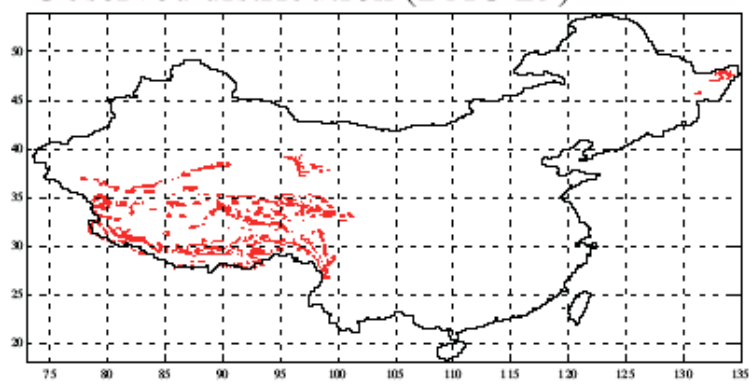

Observed distribution (BAG 24)

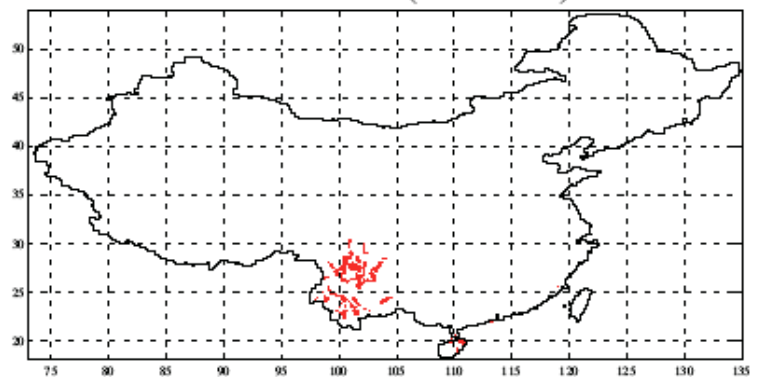

Observed distribution (BAG 25)

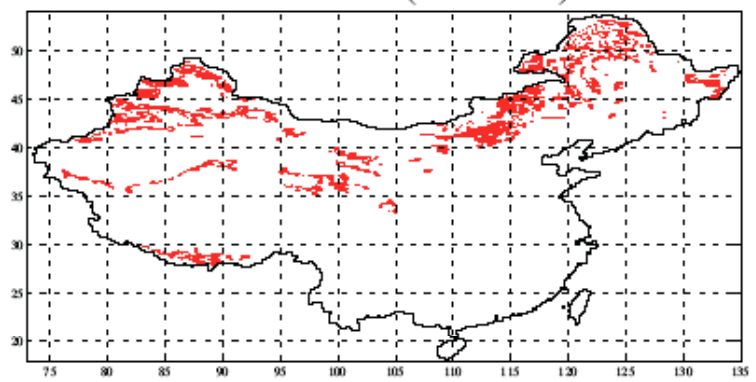

Fig. (9). Comparison of distributions between simulated and observed of shrub BAGs (BAG 21 to 23) and herb BAGs (24 and 25). 
Simulated distribution (BAG 26)

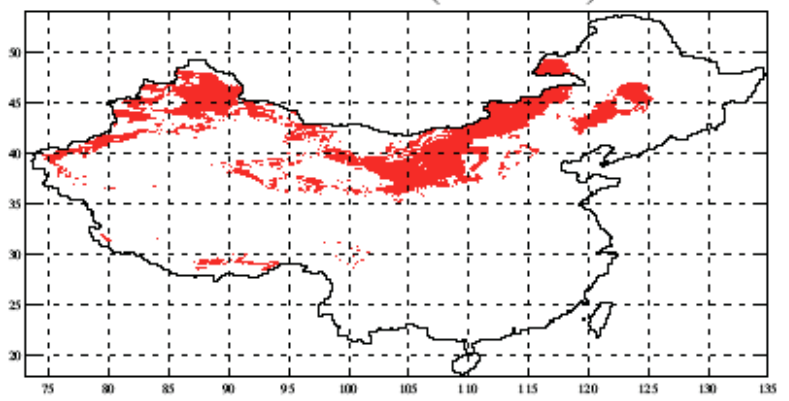

Simulated distribution (BAG 27)

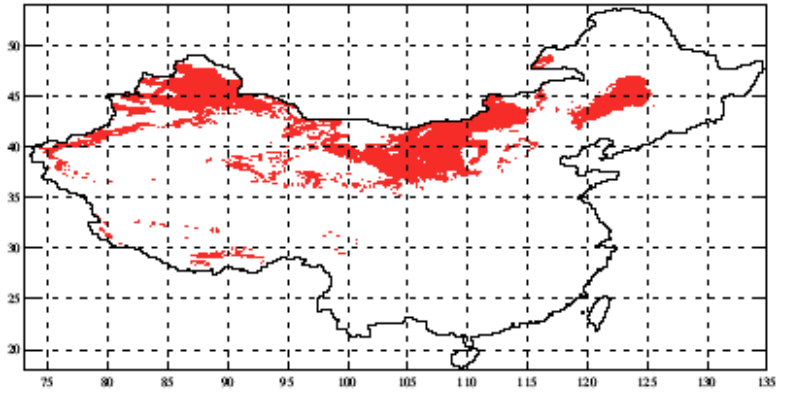

Simulated distribution (BAG 28)

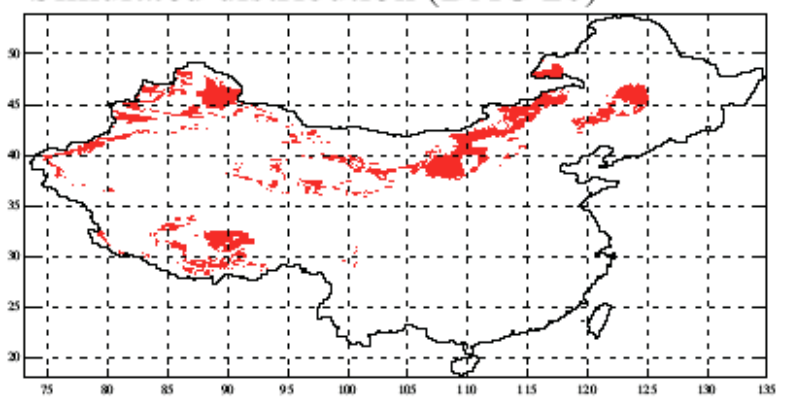

Simulated distribution (BAG 29)

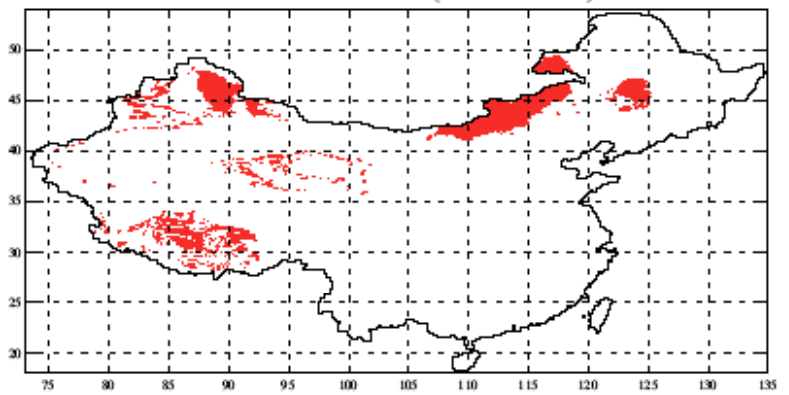

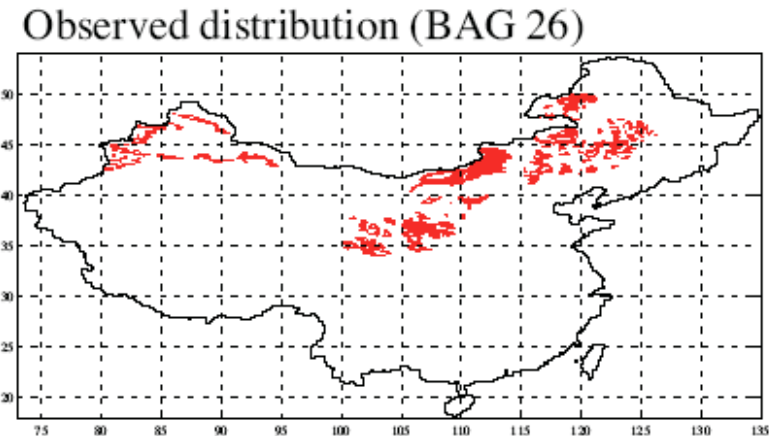
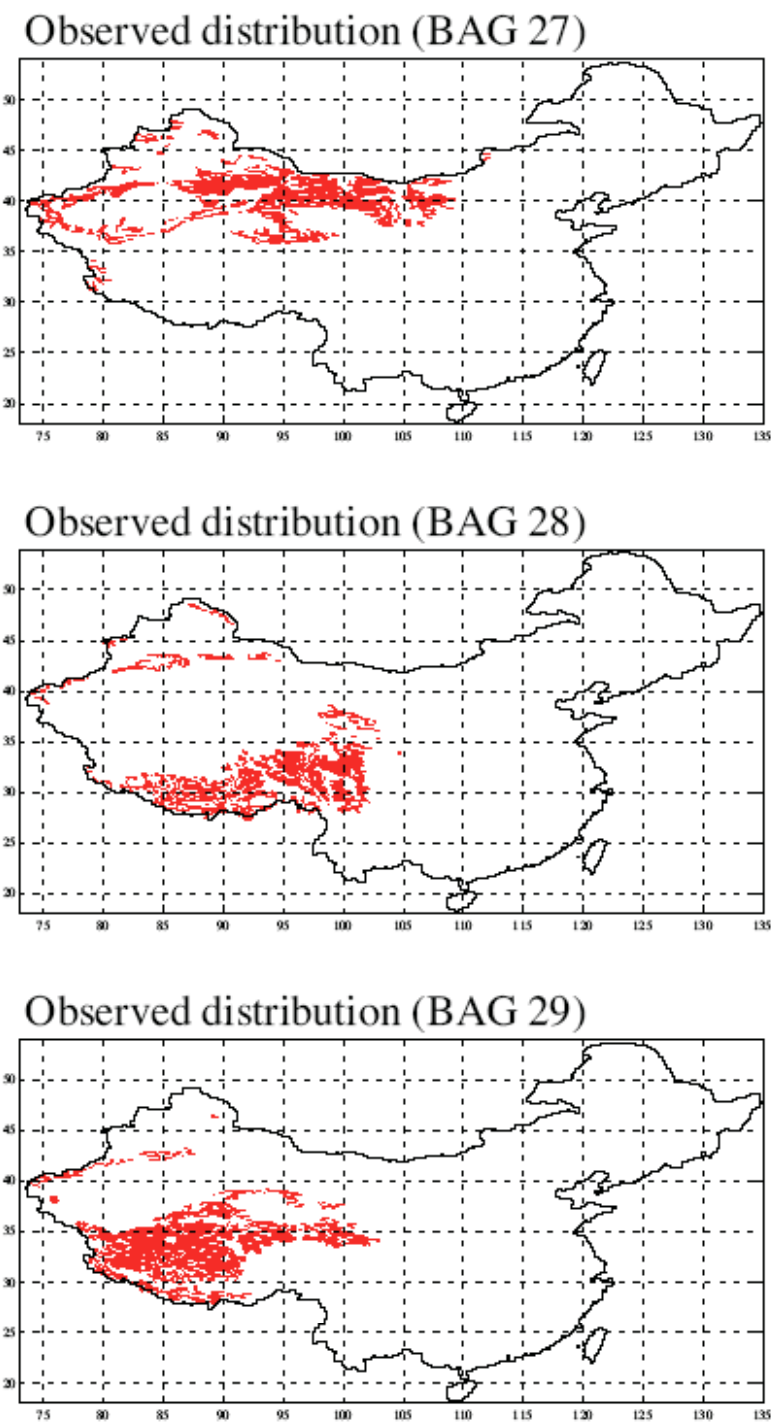

Fig. (10). Comparison of distributions between simulated and observed of herb BAGS (BAG 26 to 29).

central eastern China where there is not only temperate vegetation but also cultivated areas. Warm temperate open woodland is simulated in the valleys of south-western China.

In previous PFT assignments, subtropical evergreen broadleaved trees were assigned to only one plant functional type (Yu 1998, Yu et al. 2000, Members of China Quaternary Pollen Database 2001, Ni 2001, Weng and Zhou 2005). Here we assign the subtropical plant taxa to four distinct groups (Fig. 2, Table 4): south subtropical broadleaved evergreen trees (BAG3), mid-subtropical broadleaved evergreen trees (BAG4), subtropical mountain broadleaved evergreen trees (BAG5) and north subtropical deciduous and evergreen broadleaved mixed trees (BAG6), which are in agreement with the vegetation patterns $(\mathrm{Wu}$ 1980). BAGs 3, 4 and 6 represent the moist climate and have higher species diversity in the south-eastern forest. This 


\section{Biome Distribution}

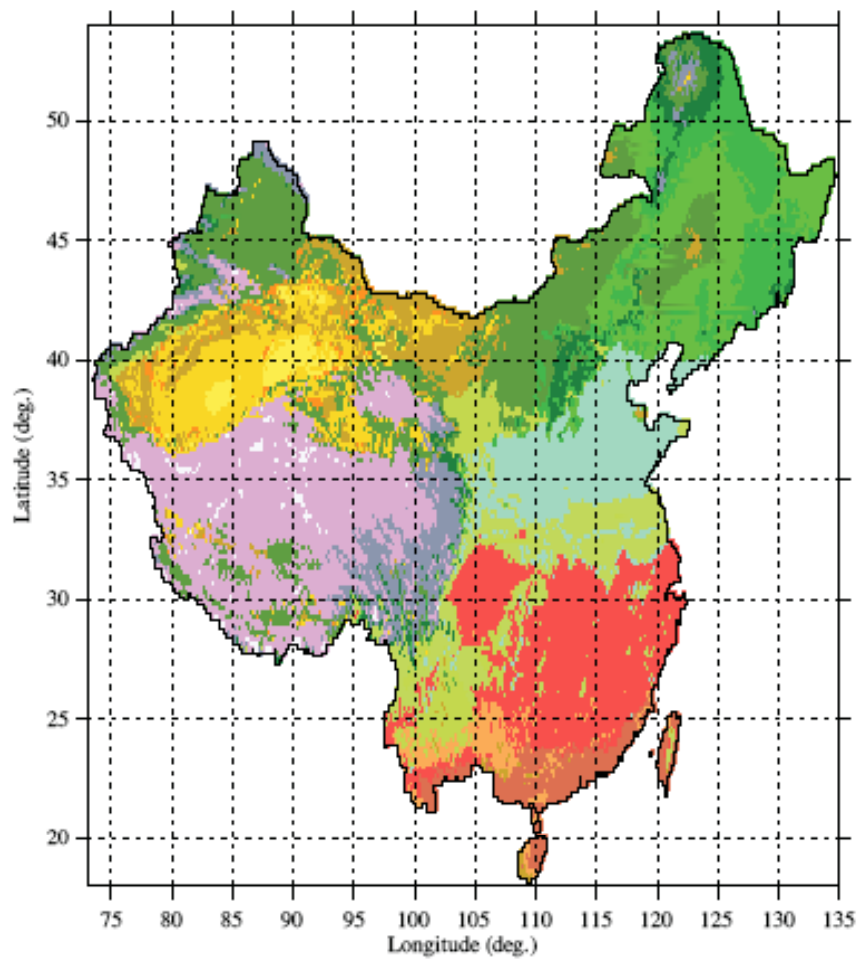

Boreal/montane forest

Cool temperate mixed forest

Cool temperate conifer forest

Temperate broadleaved deciduous forest

Warm temperate mixed forest

Warm temperate conifer forest

Warm temperate broadleaved evergreen forest

Sub-tropical forest

Tropical seasonal forest

Tropical rainforest

Cold temperate/boreal open woodland

Warm temperate open woodland

Tropical savanna

Grassland/Steppe

Shrubland

Tundra

Semi-desert

Desert

Ice or polar desert

Fig. (11). 10' $\times 10^{\prime}$ resolution potential distribution of 19 biomes based on the thresholds of 29 BAGs.

region is influenced by the East Asian Monsoon. BAG5 occurs in cold and moist areas due to the high altitude and the Indian Ocean monsoon in south-western forest.

The subtropical evergreen forest where the broadleaved or conifer trees are dominant is correctly simulated to occur over large areas, including southern and south-western China, and Taiwan. In the northern region of the subtropical forest, the model simulates warm temperate broadleaved evergreen forest in the ecotone between warm temperate mixed forest and sub-tropical forest, where the actual vegetation is a mixed evergreen-deciduous broadleaved forest.

The tropical seasonal forest is simulated in southern China, at low elevations in Taiwan, in Hainan Island, in south-eastern coastal areas, and in scattered areas on the south side of Yunnan province. The southern limit of its actual distribution is an ecotone between tropical rain forest and sub-tropical evergreen broadleaved forest (Wu 1980). The tropical rain forest is simulated in the southernmost part of the Chinese mainland and central and northern Taiwan.

\section{DISCUSSION}

In the present study, we have used the approach initially developed by Laurent et al. (2004) that defines "bioclimatic affinity groups" based on geographically referenced species ranges and related climate envelope. Such approach has proved to be more accurate than the PFT method for defining local or regional ecosystems (Laurent et al. 2004, 2008).
Simulating species, groups of plants or biomes may have different purposes. The aim of the present work is not to substitute BAGs to species but rather to allow a faster and more straightforward way to characterize ecosystems at different geographical scales, model them and lately simulate their future potential changes. Thus, our expectations here are three fold: firstly to better define the tropical and subtropical ecosystems in China; secondly, to improve the local and/or regional scale reconstructions of the ecosystems, and thirdly to define more accurate climate thresholds for simulating ecosystems at finer scales.

In order to compare quantitatively simulated ranges with observed ones we have performed kappa statistic (Monserud 1990, Monserud 1992). We have subjectively considered that kappa values (Table 8) between 0.35 and 0.50 indicate rather a fair or good match between simulated and observed distributions (17 BAGs) and kcoef greater than 0.50 corresponds to a very good match (3 BAGs). Kcoef below 0.35 indicates a weaker match. One should stress that kappa values for evaluating the degree of matching between two maps are often fixed arbitrarily.

The simulated potential tropical and tropical seasonal forests within most of Hainan Island and southern China confirm other vegetation models results (Ni et al. 2000). These model simulations are probably coherent as these areas are strongly impacted by the human agricultural activity (Fig. 1).

Although the subtropical shrubs are widely distributed in subtropical regions, they have not been reconstructed or 
Table 8. Comparison of Observed and Simulated BAGs Using Kappa Statistic

\begin{tabular}{|c|c|c|c|}
\hline BAG & Kcoef & BAG & Kcoef \\
\hline \hline 1 & 0.35 & 16 & 0.47 \\
\hline 2 & 0.38 & 17 & 0.42 \\
\hline 3 & 0.38 & 18 & 0.31 \\
\hline 4 & 0.36 & 19 & 0.37 \\
\hline 5 & 0.33 & 20 & 0.3 \\
\hline 6 & 0.35 & 21 & 0.29 \\
\hline 7 & 0.39 & 22 & 0.39 \\
\hline 8 & 0.35 & 23 & 0.28 \\
\hline 9 & 0.74 & 24 & 0.38 \\
\hline 10 & 0.38 & 25 & 0.38 \\
\hline 11 & 0.31 & 26 & 0.49 \\
\hline 12 & 0.32 & 27 & 0.46 \\
\hline 13 & 0.56 & 28 & 0.3 \\
\hline 14 & 0.31 & 29 & 0.37 \\
\hline 15 & 0.77 & & \\
\hline
\end{tabular}

BAG is the BAG number and Kcoef is the coefficient of the kappa statistic. We consider Kcoef $<0.35$ as weak match bewteen observed and simulated (9 BAGs); $0.35<$ Kcoef $<0.50$ as fair or good (17 BAGs) and Kcoef $>0.50$ as very good ( 3 BAGs).

simulated in earlier studies using PFTs. Here, we have identified four shrub groups (BAG15, 16, 17 and 18) (Figs. 7 and 8) with important species in terms of biodiversity. Among these species, BAG15, 16 and 17 are composed of pioneer taxa, such as Alchornea rugosa, Macaranga denticulata, Baeckea frutescens, Rhodomyrtus tomentosa and Loropetalum chinense. BAG18 is composed of several important species of Rhododendron which are mainly distributed in the southwestern alpine area. The statistical data-model comparisons show that except BAG18, the other three BAGs (15, 16 and 17) are well simulated with a significant kcoef: $0.77,0.47$ and 0.42 , respectively.

BAG14 represents the mangrove ecosystem, which is distributed along the sea coast (Fig. 5). This BAG is not well simulated $(\mathrm{kcoef}=0.31)$ because it is strongly related to other chemical (seawater salinity) and physical (sea level changes) variables that are not taken into account by our model.

In the temperate zone, we defined five tree BAGs $(7,8$, 11, 12 and 13), three shrub BAGs (20, 21 and 22) and three herb BAGs (25, 26 and 27). These three vegetation storeys characterize the structure and the composition of the ecosystems. We believe that predicting accurately future ecosystems changes in temperate zones requires such detailed vegetation definitions with well identified climate space for each storey. Our model has the capacity to simulate these three storeys.
Herbs and shrubs are simulated in northern and northwestern China mixed in three biomes: grassland, steppe and desert. Temperate grassland and open woodland are simulated on the edge of temperate/boreal forest, and in the areas of the Tian and Altai mountains (Figs. 4 and 11). BAG13 is composed of deciduous conifer trees such as Larix which can stand cold temperatures in winter and has a quite restricted climate space. BAG13 is simulated in montane boreal biomes with a smaller distribution than the observed one in Changbai mountain (Figs. 4 and 11) due to the low NPP during freezing winters. Its simulated range agrees well $(\mathrm{kcoef}=0.56)$ with the observed one in the Xiaoxinganling Mountains but it disagrees in the Daxingan Mountains (Figs. 4 and 11).

Warm temperate mixed forests are simulated in temperate regions, where the primary vegetation has been strongly impacted by Man particularly in eastern China where human populations are more concentrated (Fang et al. 2002).

In Tibet plateau, we defined two tree BAGs (5 and 10) and three shrub BAGs $(18,19$ and 23) and three herb BAGs (24, 28 and 29). These BAGs characterize clearly the altitudinal distribution of vegetation changes. Tree groups (BAG5 and 10) are distributed in the eastern part of Tibet Plateau with mean annual precipitation between $\sim 850$ and $\sim 1500 \mathrm{~mm} / \mathrm{yr}$. Precipitation decreases along a westward altitudinal gradient and thus the shrub and herb groups become dominating in the western part of Tibet Plateau. The alpine tundra biome is correctly predicted to occur in the Altai and Tian mountains and in Tibet Plateau (Figs. 4 and 11). The montane boreal biome is simulated in eastern Tibet Plateau which is composed of BAG10 (Figs. 4 and 11).

The BAG data-model comparisons we have performed in this work show that our approach that takes into account the modern climate and geographical distribution of species is valid for both defining coherent ecosystems and for predicting them. Modern datasets (both climate and vegetation) have the advantage of being available on a geographical grid system. However, the modern plants distributions in several areas in China are strongly impacted by human activities (Fig. 1). Thus, acquiring greater confidence in our predicting capacity will require a validation of our model with observed data that are less disturbed such as fossil records. However, building a network of fossil data at the scale of China will require an additional effort.

\section{CONCLUSIONS}

Twenty-nine Bioclimatic Affinity Groups of plants (13 tree, 10 shrub and 6 herb groups) were defined from a clustering of 196 dominant plant species in China. These BAGs are characterized by their phenology, the geographical distribution of the species they are composed of and their 73 related climate variables. The approach we have used (Laurent et al. 2004) provides quite detailed and robust groups of plants, including trees, shrubs and herbs with well defined climate requirements. These groups may provide a more detailed structure and composition of the vegetation 
ecosystems in the tropical and sub-tropical areas than the plant functional types based on pollen data (Yu et al. 1999). The BAGs and biomes simulations show that the climate thresholds that we have defined are coherent and may potentially be used to simulate future ecosystems distributions in China.

\section{ACKNOWLEDGEMENTS}

K.Y. Huang was supported by a scholarship from the French Embassy in China during his PhD thesis. Funding for this research was provided by the National Natural Science Foundation of China (Grant No. 40331011, 40772113 and 40730103) and by the Belgian Research Foundation F.R.S.FNRS grant $\mathrm{N}^{\circ}$ 1.5.179.07 which are gratefully acknowledged. We thank Eric Favre for digitizing the geographical distribution of Larix in Siberia. This is an ISEM 2009-116 contribution.

\section{REFERENCES}

Díaz, S \& Cabido, M (1997) Plant functional types and ecosystem function in relation to global change: a multiscale approach. Journal of Vegetation Science, 8, 463-74.

Fang, JY, Song, YC, Liu, HY, \& Piao, SL (2002) Vegetation-Climate relationship and its application in the division of vegetation zone in China. Acta Botanica Sinica, 44 (9), 1105-22.

Foley, J, Prentice, I, Ramankutty, N, Levis, S, Pollard, D, Sitch, S \& Haxeltine, A (1996) An integrated biosphere model of land surface processes, terrestrial carbon balance, and vegetation dynamics. Global Biogeochemical Cycles, 10 (4), 603-28.

Haxeltine, A \& Prentice, IC (1996) BIOME3: An equilibrium terrestrial biosphere model based on ecophysiological constraints, resource availability, and competition among plant functional types. Global Biogeochemical Cycles, 10, 693-709.

Hou, XY (2001) The Vegetation Atlas of China (1: 1000000), Science Press: Beijing, China.

Huang, KY, Zheng, Z, \& Cheddadi, R (2008) Atlas of plants distributions and related climate in China: China Review Academic Publishers: Hongkong 1-277.

Hubert, B, François, L, Warnant, P \& Strivay, D (1998) Stochastic generation of meteorological variables and effects on global models of water and carbon cycles in vegetation and soils. Journal of Hydrology, 212(13): 318-34.

IGBP (1990) The international Geosphere-Biosphere Programme: The initial core projects. Report 12, Stockholm, 329-30.

Institute of Botany, (1985-1987) The Chinese Academy of Sciences. Illustrated flora of higher plants in China. Science Press Beijing: China, vols. 1-4.

IPCC (2001) Climate change 2001-Synthesis report: third assessment report of the intergovernmental panel on climate change. Cambridge University Press: UK, 1-10.

IPCC (2007) In climate change 2007: the physical science basis. Contribution of working group I to the fourth assessment report of the intergovernmental panel on climate change. Cambridge University Press: UK, 1-18.

Ward, JH Jr (1963) Hierarchical grouping to optimize an objective function. Journal of the American Statistical Association, 58, 236-44.

Joussaume, S, \& Taylor, KE (1995) Status of the paleoclimate modeling intercomparison project (PMIP). In: Gates WL (Ed), Proceedings of the first international AMIP scientific conf, Monterey, CA. WCRP, 425-30.

Kaplan, JO (2001) Geophysical applications of vegetation modeling, Ph.D. thesis, Lund Univ., Lund, Sweden.

Laurent, J-M, Bar-Hen, A, François, L, Ghislain, M \& Cheddadi, R (2004) Refining vegetation simulation models: from plant functional types to bioclimatic affinity groups of plants. Journal of Vegetation Science, 15, 739-46.
Laurent, J-M, François, L, Bar-Hen, A, Bel, L \& Cheddadi, R (2008) European Bioclimatic Affinity Groups: data-model comparisons. Global \& Planetary Change, 28-40.

Matthews, E (1983) Global vegetation and land use: new high resolution data bases for climate studies. Journal of Climate and Applied Meteorology, 22, 474-87.

Melillo, J, McGuire, A, Kicklighter, D, Moore III, B, Vorosmarty, C, \& Schloss, A (1993) Global climate change and terrestrial net primary production. Nature, 363, 234-40.

Members of China Quaternary Pollen Database (Chen, XD) (2001) Simulation of China biome reconstruction based on pollen data from surface sediment samples. Acta Botanica Sinica, 43, 201-09.

Monserud, RA \& Leemans, R (1992) Comparing global vegetation maps with Kappa statistic. Ecological Modelling, 62, 275-93.

Monserud, RA (1990) Methods for Comparing Global Vegetation Maps, WP-90-40.

New, M, Lister, D, Hulme, M \& Makin, I (2002) A high-resolution data set of surface climate over global land areas. Climate Research, 21, 125.

Ni, J (2001) Plant Functional Types and Biomes of China at a Regional Scale. Acta Phytoecologica Sinica, 43 (4), 419-25.

Ni, J, Sykes, MT, Prentice, IC, \& Cramer, W (2000) Modelling the vegetation of China using the process-based equilibrium terrestrial biosphere model BIOME3. Global Ecology \& Biogeography, 9, 463-79.

Otto, D, Rasse, D, Kaplan, J, Warnant, P \& François, L (2003) Biospheric carbon stocks reconstructed at the Last Glacial Maximum: comparison between general circulation models using prescribed and computed sea surface temperatures. Global and Planetary Change, 33, 117-38.

Prentice, IC, Cramer, W, Harrison, SP, Leemans, R, Monserud, RA \& Solomon, AM (1992) A global biome model based on plant physiology and dominance, soil properties and climate. Journal Biogeography, 19, 117-34.

Prentice, IC, Guiot, J, Huntley, B, Jolly, D \& Cheddadi, R (1996) Reconstructing biomes from palaeoecological data: a general method and its application to European pollen data at 0 and $6 \mathrm{ka}$. Climate Dynamics, 12, 185-94.

Prentice, IC, Harrison, SP, Jolly, D, \& Guiot, J (1997) the climate and biomes of Europe at $6000 \mathrm{yr}$ bp: comparison of model simulations and pollen-based reconstructions. Quaternary Sciences Reviews, 17, 6-7.

R Development Core Team (2007) R: A language and environment for statistical computing. $\mathrm{R}$ foundation for statistical computing, Vienna, Austria. ISBN 3-900051-07-0, URL http://www.Rproject.org.

Semerikov, VL \& Lascoux, M (1999) Genetic relationship among Eurasian and American Larix species based on allozymes. Heredity, 83, 6270.

Smith, TM, Shugart, HH \& Woodward, FI (1996) Plant Functional Types. Cambridge University Press: UK.

Sun, XJ, Song, CQ \& Chen, XD (1999) China Quaternary Pollen Database (CPD) and Biome 6000 Project. Advance in Earth Sciences, 14, 407-11.

Warnant, P (1999) Modélisation du cycle du carbone dans la biosphère continentale à l'échelle globale. Thèse de doctorat, Faculté des Sciences. Université de Liège.

Warnant, P, François, L, Strivay, D \& Gérard, JC (1994) CARAIB: A global model of terrestrial biological productivity. Global Biogeochemical Cycles, 8(3), 255-70.

Weng, ES, Zhou, GS (2005) Defining Plant functional types in China for global change studies. Acta Phytoecologica Sinica, 29(1), 81-97.

Wu, ZY (1980) Vegetation of China. Science Press Beijing: China.

Yu, G (1998) Preliminary study on pollen-based biomization and Chinese biome mapping of 6000 a BP. Acta Botanica Sinica, 40, 665-74.

Yu, G, Chen, XD, Ni, J, Cheddadi, R, Guiot, J, Han, H, Harrison, SP, Huang, C, Ke, M, Kong, Z, Li, S, Li, W, Liew, P, Liu, G, Liu, J, Liu, Q, Liu, KB, Prentice, IC, Qui, W, Ren, G, Song, C, Sugita, S,

Sun, X, Tang, L, Van Campo, E, Xia, Y, Xu, Q, Yan, S, Yang, X, Zhao, J \& Zheng, Z (2000) Palaeovegetation of China: a pollen 
(C) Huang et al.; Licensee Bentham Open.

This is an open access article licensed under the terms of the Creative Commons Attribution Non-Commercial License (http://creativecommons.org/licenses/by$\mathrm{nc} / 3.0 /$ ), which permits unrestricted, non-commercial use, distribution \& reproduction in any medium, provided the work is properly cited. 